\title{
UK Renal Registry 19th Annual Report: Chapter 5 Survival and Causes of Death in UK Adult Patients on Renal Replacement Therapy in 2015: National and Centre-specific Analyses
}

\author{
Shona Methven ${ }^{a}$, Retha Steenkamp ${ }^{a}$, Simon Fraser ${ }^{b}$ \\ a'UK Renal Registry, Bristol, UK; ${ }^{\mathrm{b}}$ University of Southampton, UK
}

\section{Keywords}

Causes of death . Comorbidity . Dialysis . End stage renal disease (ESRD). Established renal failure (ERF) · Haemodialysis . Outcome . Peritoneal dialysis . Renal replacement therapy (RRT) · Survival · Transplant · Vintage

\section{Summary}

- Short-term (90 day) age-adjusted survival of incident RRT patients in 2014 was static compared with 2013 (96.8\% versus 96.9\%).

- One year after 90 day age adjusted survival for incident RRT patients in the 2014 cohort fell slightly to 90.2\% compared with the previous year (91.4\%).

- There was a difference in one year after 90 day incident survival by age group and diagnosis of diabetes: patients with diabetes aged $<45$ years have worse one year after 90 day survival than patients without diabetes, but for older patients with diabetes $(\geqslant 45$ years) survival was similar compared to those without diabetes.
- One year age adjusted survival for prevalent dialysis patients was static at $88.3 \%$ in the 2014 cohort, compared with $88.6 \%$ in the 2013 cohort. Age adjusted one year survival for prevalent dialysis patients with diabetic primary renal disease has been declining slightly from 2012 onwards.

- Centre and UK country variability was evident in incident and prevalent patient survival after adjusting to age 60 . Further adjustment for comorbidity was not possible due to missing data.

- The relative one year risk of death for prevalent RRT patients compared with the general population was approximately 22.0 for age group 35-39 compared with 2.3 at age $85+$ years, but the relative risk of death for younger patients has improved over time.

- In the prevalent RRT population, cardiovascular disease was the most common cause of death and accounted for $22 \%$ of deaths, with infection accounting for $21 \%$. In 2014 treatment withdrawal accounted for $18 \%$ of deaths and this represents an increase in recent years from historical levels.

\begin{tabular}{ll}
\hline KARGER & $\begin{array}{l}\text { C } 2017 \text { The UK Renal Registry } \\
\text { Published by S. Karger AG, Basel Karger }\end{array}$ \\
$\begin{array}{l}\text { Fax +4161306 } 1234 \\
\text { E-Mail karger@karger.com } \\
\text { www.karger.com/nef }\end{array}$ & $\begin{array}{l}\text { This article is licensed under the Creative Commons Attribution- } \\
\text { NonCommercial-NoDerivatives 4.0 International License (CC BY- } \\
\text { NC-ND) (http://www.karger.com/Services/OpenAccessLicense). } \\
\text { Usage and distribution for commercial purposes as well as any } \\
\text { distribution of modified material requires written permission. }\end{array}$
\end{tabular}

Retha Steenkamp

UK Renal Registry, Southmead Hospital, Southmead Road,

Bristol, BS10 5NB, UK

Email: renalregistry@renalregistry.nhs.uk 


\section{Introduction}

The analyses presented in this chapter examine a) survival from the start of renal replacement therapy (RRT) of adult patients; b) survival amongst prevalent adult dialysis patients alive on 31st December 2014; c) the death rate in the UK compared to the general population; d) the causes of death for incident and prevalent adult patients. They encompass the outcomes of the total incident adult UK RRT population (2014) reported to the UK Renal Registry (UKRR), including the 19.2\% who started on peritoneal dialysis and the $7.7 \%$ who received a pre-emptive renal transplant. These results are therefore a true reflection of the outcomes in the whole UK adult incident RRT population. Analyses of survival within the first year of starting RRT include patients who were recorded as having started RRT for established renal failure (as opposed to acute kidney injury) but who had died within the first 90 days of starting RRT, a group excluded from most other countries' registry data. As is common in other countries, survival analyses are also presented for the first year after 90 days.

The term established renal failure (ERF) used throughout this chapter is synonymous with the terms end stage renal failure (ESRF) and end stage renal disease (ESRD) which are in more widespread international usage. Within the UK, patients have disliked the term 'end stage'; the term ERF was endorsed by the English National Service Framework for Renal Services, published in 2004.

Since 2006, the UKRR has openly reported and published centre attributable RRT survival data. These are raw data which must be interpreted with caution. The UKRR adjusts for the different age distributions of patients in different centres, but lacks sufficient data from many participating centres to allow adjustment for primary renal diagnosis, other comorbidities at start of RRT (comorbidity, especially diabetes, is a major factor associated with survival [1-3]) and ethnic origin, which have been shown to have an impact on outcome (for instance, better survival is expected in centres with a higher proportion of Black and South Asian patients) [4]. This lack of data on the centre level case-mix makes interpretation of any apparent difference in survival between centres and UK countries difficult. Despite the uncertainty about apparent differences in outcome, any centre which appears to be an outlier will be subject to the UKRR clinical governance procedures as set out in chapter 2 of the 2009 UKRR Report [5].

\section{Methods}

The unadjusted survival probabilities (with 95\% confidence intervals) were calculated using the Kaplan-Meier method, in which the probability of surviving more than a given time can be estimated for all members of a cohort of patients overall or by subgroup such as age group, but without any adjustment for confounding factors such as age that affect the chances of survival. Where centres are small, or the survival probabilities are greater than $90 \%$, the confidence intervals are only approximate.

In order to estimate the difference in survival of different subgroups of patients within the cohort, a stratified proportional hazards model (Cox) was used where appropriate. The results from the Cox model were interpreted using a hazard ratio. When comparing two groups, the hazard ratio is the ratio of the estimated hazard for group A relative to group B, where the hazard is the risk of dying at time $t$ given that the individual has survived until this time. The underlying assumption of a proportional hazards model is that the hazard ratio remains constant throughout the period under consideration. Whenever used, the assumptions of the proportional hazards model were tested by plotting the $\log (-\log ($ survival $))$ versus the log of survival time or by testing time dependent covariates in the model.

To allow for comparisons between centres with differing age distributions, survival analyses were adjusted for age and reported as survival adjusted to age 60 . This gives an estimate of what the survival would have been if all patients in that centre had been aged 60 at the start of RRT. This age was chosen because it was approximately the average age of patients starting RRT 16 years ago at the start of the UKRR's data collection. The average age of patients commencing RRT in the UK has recently stabilised around an age of 62 years, but the UKRR has maintained age adjustment to 60 years for comparability with all previous years' analyses. Diabetic patients were included in all analyses unless stated otherwise and for some analyses, diabetic and non-diabetic patients were analysed separately and compared. Non-diabetic patients were defined as all patients excluding those patients with diabetes as the primary renal disease.

Centre variability for incident and prevalent patient survival was analysed using a funnel plot. For any number of patients in the incident or prevalent cohort (x-axis), one can identify whether any given survival probability (y-axis) falls within, plus or minus two standard deviations (SDs) from the national mean (solid lines, 95\% limits) or three SDs (dotted lines, 99.9\% limits). All analyses were undertaken using SAS 9.3.

\section{Definition of RRT start date}

The incident survival figures quoted in this chapter are from the first day of RRT whether with dialysis or a pre-emptive transplant. In the UKRR all patients starting RRT for ERF are included from the date of the first RRT treatment wherever it took place (a date currently defined by the clinician) if the clinician considered the renal failure irreversible. Should a patient recover renal function within 90 days they were then excluded. These UK data therefore may include some patients who died within 90 days who had developed acute, potentially reversible renal failure but were recorded by the clinician as being in irreversible ERF.

Previously, the UKRR asked clinicians to re-enter a code for ERF in patients initially coded as having acute renal failure once it had become clear that there was no recovery of kidney function. 
However, adherence to this requirement was very variable, with some clinicians entering a code for ERF only once a decision had been made to plan for long-term RRT [6]. All UK nephrologists have now been asked to record the date of the first haemodialysis session and to record whether the patient was considered to have acute kidney injury (acute renal failure) or to be in ERF at the time. For patients initially categorised as 'acute', but who were subsequently categorised as ERF, the UKRR assigns the date of this first 'acute' session as the date of start of RRT.

UKRR analyses of electronic data extracted for the immediate month prior to the start date of RRT provided by clinicians highlighted additional inconsistencies in the definition of this first date when patients started on peritoneal dialysis, with the date of start reported to the UKRR being later than the actual date of start. These findings are described in detail in chapter 13 of the 2009 Annual Report [6]. This concern is unlikely to be unique to the UK, but will be common to analyses from all renal centres and registries.

In addition to these problems of defining day 0 within one country, there is international variability when patient data are collected by national registries with some countries (often for financial re-imbursement or administrative reasons) defining the 90th day after starting RRT as day 0, whilst others collect data only on those who have survived 90 days and report as zero the number of patients dying within the first 90 days.

Thus, as many other national registries do not include reports on patients who do not survive the first 90 days, survival from 90 days onwards is also reported to allow international comparisons. This distinction is important, as there is a much higher death rate in the first 90 days, which would distort comparisons.

\section{Methodology for incident patient survival}

The incident population is defined as all patients over 18 who started RRT at UK renal centres. Patients were considered 'incident' at the time of their first RRT, thus patients re-starting dialysis after a failed transplant were not included in the incident RRT cohort (see appendix B for a detailed definition of the incident (take-on) population).

For incident survival analyses, patients newly transferred into a centre who were already on RRT were excluded from the incident population for that centre and were counted at the centre at which they started RRT. Some patients recovered renal function after more than 90 days but subsequently returned to RRT and for these patients the most recent start of RRT was used.

The incident survival cohort was NOT censored at the time of transplantation and therefore included the survival of the $7.7 \%$ who received a pre-emptive transplant. An additional reason for not censoring was to facilitate comparison between centres. Centres with a high proportion of patients of South Asian and Black origin are likely to have a healthier dialysis population, because South Asian and Black patients are less likely to undergo early transplantation [7], and centres with a high pre-emptive transplant rate are likely to have a less healthy dialysis population as transplantation selectively removes fitter patients. However, censoring at transplantation was performed in the 1997-2014 cohort to establish the effect on long term survival by age group and also in the 2011-2014 cohort to investigate the effect on the outlying status of centres.

The one year incident survival is for patients who started RRT from 1st October 2013 until the 30th September 2014 and followed up for one full year (e.g. patients starting RRT on 1st December 2013 were followed through to 30th November 2014). The 2015 incident patients could not be analysed as they had not yet been followed for a sufficient length of time. For analysis of one year after 90 day survival, patients who started RRT from 1st October 2013 until 30th September 2014 were included in the cohort and they were followed up for a full year after the first 90 days of RRT.

Two years' incident data (2013-2014) were combined to increase the size of the patient cohort, so that any differences between the four UK countries can be more reliably identified. To help identify any centre differences in survival from the small centres (where confidence intervals are large), an analysis of one year after 90 day survival using a rolling four year combined incident RRT cohort from 2011 to 2014 was also undertaken. A 10 year rolling cohort was used when analysing trends over time and for long term survival, a cohort from 1997 to 2014 was analysed.

The death rate per 1,000 patient years was calculated by dividing the number of deaths by the person years exposed. Person years exposed are the total years at risk for each patient (until death, recovery or lost to follow up). The death rate is presented by age group and UK nation.

Adjustment of one year after 90 day survival for the effect of comorbidity was undertaken using a rolling four year combined incident RRT cohort from 2011 to 2014. Twenty-eight centres returned $\geqslant 85 \%$ of comorbidity data for patients in the combined cohort. Adjustment was first performed to a mean age of 60 years, then to the average distribution of primary diagnoses for the 28 centres. The individual centre data were then further adjusted for average distribution of comorbidity present at these centres.

\section{Methodology for prevalent dialysis patient survival}

The prevalent dialysis patient group was defined as all patients over 18 years old, alive and receiving dialysis on 31st December 2014 who had been on dialysis for at least 90 days at one of the UK adult renal centres. Prevalent dialysis patients on 31st December 2014 were followed-up in 2015 and were censored at transplantation. When a patient is censored at transplantation, this means that the patient is considered as alive up to the point of transplantation, but the patient's status post-transplant is not considered.

As discussed in previous reports, comparison of survival of prevalent dialysis patients between centres is complex. Survival of prevalent dialysis patients can be studied with or without censoring at transplantation and it is common practice in some registries to censor at transplantation. Censoring could cause apparent differences in survival between those renal centres with a high transplant rate and those with a low transplant rate, especially in younger patients where the transplant rate is highest. Censoring at transplantation systematically removes younger fitter patients from the survival data. The differences are likely to be small due to the relatively small proportion of patients being transplanted in a given year compared to the whole dialysis population (about 12\% of the dialysis population aged under 65 and about $2 \%$ of the population aged 65 years and over). To allow comparisons with other registries the survival results for prevalent dialysis patients CENSORED for transplantation have been quoted. To understand survival of patients, including survival following transplantation, the incident patient analyses should be viewed. 
The effect of not censoring at transplantation was performed in the 2014 cohort to investigate the effect on the outlying status of centres.

\section{Methodology for comparing mortality in prevalent $R R T$}

patients with mortality in the general population

Data on the UK population in mid-2014 and the number of deaths in each age group in 2014 were obtained from the Office of National Statistics [8]. The age specific UK death rate was calculated as the number of deaths in the UK per thousand people in the population. The age specific expected number of deaths in the RRT population was calculated by applying the UK age specific death rate to the total of years exposed for RRT patients in that age group. This is expressed as deaths per 1,000 patient years. The age specific number of RRT deaths is the actual number of deaths observed in 2014 in RRT patients. The RRT observed death rate was calculated as number of deaths observed in 2014 per 1,000 patient years exposed. Relative risk of death was calculated as the ratio of the observed and expected death rates for RRT patients. The death rate was calculated for the UK general population by age group and compared with the same age group for prevalent patients on RRT on 31st December 2014.

Methodology of causes of death

The EDTA-ERA Registry codes for causes of death were used. These have been grouped into the following categories:

- Cardiac disease

- Cerebrovascular disease

- Infection

- Malignancy

- Treatment withdrawal

- Other

- Uncertain

Completeness of cause of death data was calculated for all prevalent patients on RRT that died in a specific year with cause of death data completed for that year. Patients that were lost to follow up or that recovered were not included in the cause of death completeness calculation.

Adult patients aged 18 years and over from England, Wales, Scotland and Northern Ireland were included in the analyses of cause of death. The incident patient analysis included all patients starting RRT in the years 2000-2014. Analysis of prevalent patients included all those aged over 18 years and receiving RRT on 31st December 2014 and followed-up for one year in 2015.

\section{Results \\ Incident (new RRT) patient survival}

\section{Overall survival}

The 2014 incident RRT cohort included 7,251 patients who started RRT. Survival at 90 days (adjusted to age 60) for the 2014 cohort was $96.8 \%$, and was unchanged compared to the previous year (96.9\%) (table 5.1). One year after 90 days survival for incident patients starting RRT in 2014 (adjusted to age 60) fell slightly compared to the previous year: $90.2 \%$ compared to $91.4 \%$ in the 2013 cohort (table 5.1).

\section{Survival by UK country}

Survival at 90 days was highest in Scotland compared with the other nations (table 5.2), while one year after 90 day survival also differed between countries, with England having the highest survival (table 5.2). However, there are two important caveats for the interpretation of these data; they have not been adjusted for differences in primary renal diagnosis, ethnicity, socio-economic status or comorbidity, which may differ by country. Secondly, there are known regional differences in the life expectancy of the general population within the UK (which may be explained by some of the factors outlined above plus others). These general population differences are likely to contribute to the variation in survival between renal centres and UK countries. To illustrate this, table 5.3 shows general population life expectancy of the UK countries for the period 2013-2015.

Table 5.1. Survival of incident RRT patients, 2014 cohort

\begin{tabular}{lcccr}
\hline Interval & Unadjusted survival (\%) & Adjusted survival (\%) & $95 \%$ CI & $N$ \\
\hline Survival at 90 days & 95.5 & 96.8 & $96.3-97.3$ & 7,251 \\
Survival one year after 90 days & 87.1 & 90.2 & $89.4-91.1$ & 6,896 \\
\hline
\end{tabular}

Table 5.2. Incident RRT survival across the UK countries, combined two year cohort (2013-2014), adjusted to age 60

\begin{tabular}{lccccc}
\hline Interval & England & N Ireland & Scotland & Wales & UK \\
\hline Survival at 90 days (\%) & 96.7 & 96.5 & 98.0 & 96.6 & 96.8 \\
$95 \%$ CI & $96.4-97.1$ & $94.9-98.1$ & $97.2-98.7$ & $95.5-97.6$ & $96.5-97.2$ \\
Survival 1 year after 90 days (\%) & 91.1 & 89.5 & 89.8 & 88.2 & 90.8 \\
$95 \%$ CI & $90.5-91.6$ & $86.6-92.4$ & $88.1-91.6$ & $86.2-90.3$ & $90.2-91.3$ \\
\hline
\end{tabular}


Table 5.3. Life expectancy in years in the UK countries, 20132015 (source ONS [8])

\begin{tabular}{lccccc}
\hline \multirow{2}{*}{ Country } & \multicolumn{2}{c}{ At birth } & & \multicolumn{2}{c}{ At age 65 } \\
\cline { 2 - 3 } \cline { 5 - 6 } \cline { 5 - 6 } & Male & Female & & Male & Female \\
\hline England & 79.4 & 83.1 & & 18.6 & 21.0 \\
Northern Ireland & 78.3 & 82.3 & & 18.1 & 20.5 \\
Scotland & 77.1 & 81.1 & & 17.3 & 19.7 \\
Wales & 78.4 & 82.3 & & 18.1 & 20.5 \\
UK & $\mathbf{7 9 . 1}$ & $\mathbf{8 2 . 8}$ & & $\mathbf{1 8 . 5}$ & $\mathbf{2 0 . 9}$ \\
\hline
\end{tabular}

\section{Survival by modality}

It is not possible to make truly valid comparisons of survival of cohorts of patients starting different RRT modalities, as modality selection is not random. In the $\mathrm{UK}$, the cohort of patients starting peritoneal dialysis was younger and received a transplant more quickly than those starting haemodialysis. The age adjusted one year after 90 days survival estimates for incident patients starting RRT on haemodialysis (HD) and peritoneal dialysis (PD) in 2014 were $88.4 \%$ and $92.8 \%$ respectively, with both $\mathrm{HD}$ and $\mathrm{PD}$ patient survival falling slightly from the previous year (figure 5.1). This is the first time in five years that the one year after 90 days survival on haemodialysis has declined. PD patients' survival has remained relatively static over the last five years, with a small decline observed this year (figure 5.1).

\section{Survival by age}

Tables 5.4 and 5.5 show survival for the 2014 incident RRT cohort divided by age ( $\geqslant 65$ years and $<65$ years). Short term survival (at 90 days) decreased marginally for the younger age group, while it increased for those $\geqslant 65$ years compared with the 2013 cohort (98.1 to $97.8 \%$ for those aged $18-64$ years and 91.6 to $93.2 \%$ for
Table 5.4. Unadjusted 90 day survival of incident RRT patients, 2014 cohort, by age

\begin{tabular}{lccc}
\hline Age group & Survival (\%) & $95 \%$ CI & $N$ \\
\hline $18-64$ & 97.8 & $97.3-98.2$ & 3,667 \\
$\geqslant 65$ & 93.2 & $92.3-94.0$ & 3,584 \\
All ages & 95.5 & $95.0-96.0$ & 7,251 \\
\hline
\end{tabular}

Table 5.5. Unadjusted one year after day 90 survival of incident RRT patients, 2014 cohort, by age

\begin{tabular}{lccc}
\hline Age group & Survival (\%) & $95 \%$ CI & $N$ \\
\hline $18-64$ & 93.3 & $92.4-94.1$ & 3,562 \\
$\geqslant 65$ & 80.6 & $79.2-81.9$ & 3,334 \\
All ages & 87.1 & $86.3-87.9$ & 6,896 \\
\hline
\end{tabular}

those $\geqslant 65$ years respectively). There was a small decline in one year after 90 day survival for both age groups compared to the 2013 cohort. There was a steep decline in survival with advancing age (figure 5.2).

There was a curvilinear increase in the death rate per 1,000 patient years with increasing age for the one year period from 90 days after RRT start (figure 5.3). The overall death rate in Wales was higher than in the other UK countries, mostly due to a higher death rate in Wales for patients $\geqslant 55$ years old (figure 5.3) and a higher overall median age compared to other UK countries. A similar finding is reported in table 5.12, where there was evidence that the one year death rate in prevalent dialysis patients (2014 cohort) was higher in Wales compared to England. This is also consistent with the survival figures reported in table 5.2.

Figure 5.4 shows the long-term survival of incident patients from day 0 (start of RRT), according to age at

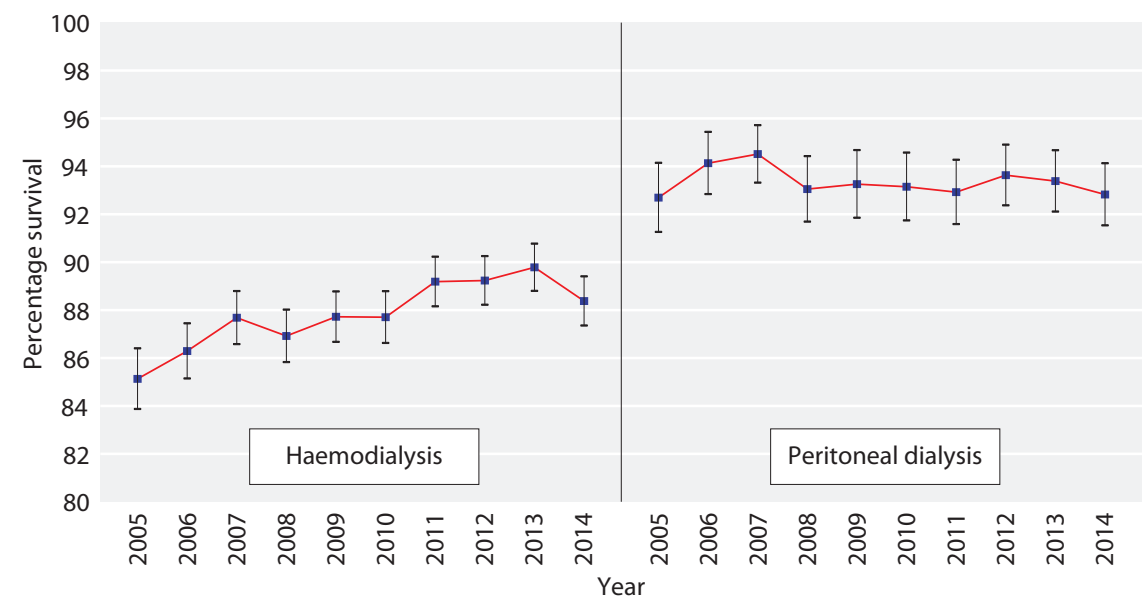

Fig. 5.1. Trend in one year after 90 day incident patient survival by first modality, 2005-2014 cohorts (adjusted to age 60, excluding patients whose first modality was transplantation) 


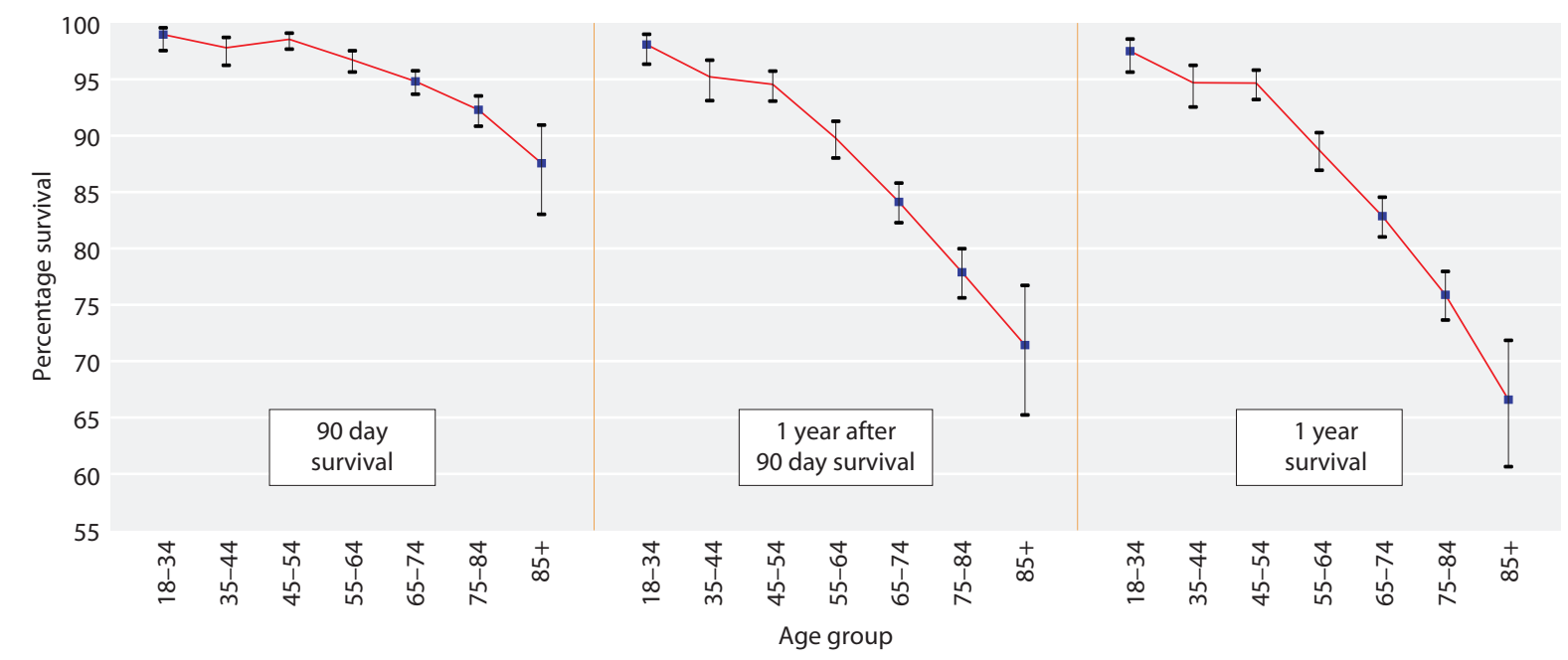

Fig. 5.2. Unadjusted survival of incident RRT patients by age group, 2014 cohort

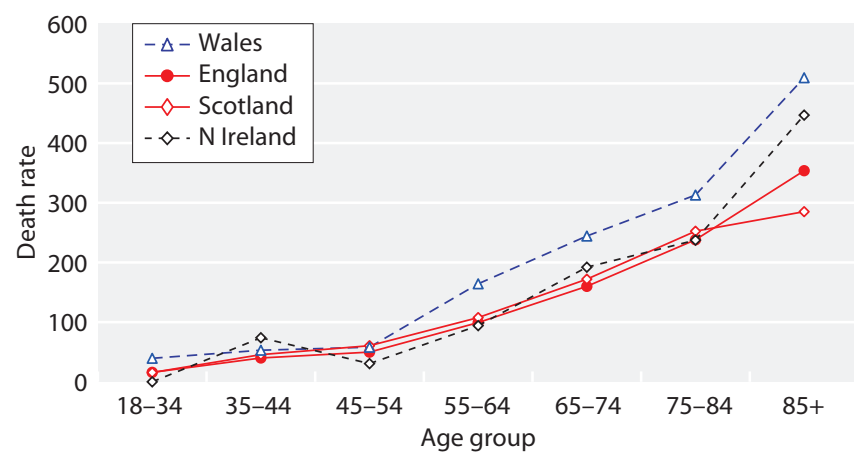

Fig. 5.3. One year after 90 days death rate per 1,000 patient years by UK country and age group for incident RRT patients, 20112014 cohort

RRT start. More than $50 \%$ of patients who were aged between 45-54 years when starting RRT survived for over 10 years. Median survival for those aged between 55-64 years at RRT start was around 6.0 years and median survival for those aged between $65-74$ years was approximately 3.5 years.
Figure 5.5 illustrates the survival of incident patients, excluding those who died within the first 90 days and shows that median survival of patients aged between 55-64 years was approximately 6.5 years and median survival of patients aged between 65-74 years was approximately 4 years. These survival results are slightly better than survival from day 0 for the same age groups, as would be expected due to the higher mortality observed in the first 90 days of treatment (figure 5.4).

Censoring at transplantation removes the fittest patients from the survival cohort and affects the appearance of the longer-term outcomes of the younger patients (who are most likely to have undergone transplantation). Without censoring, the 10 -year survival for patients aged 18-34 years was $83.7 \%$ (figure 5.4), however if survival is censored at transplantation this falls dramatically to $58.1 \%$ (data not shown). The 10 year survival without and with censoring at transplantation were $70.7 \%$ and $43.8 \%$ for age group $35-44$ years and $54.6 \%$ and $30.7 \%$ for age group $45-54$ years

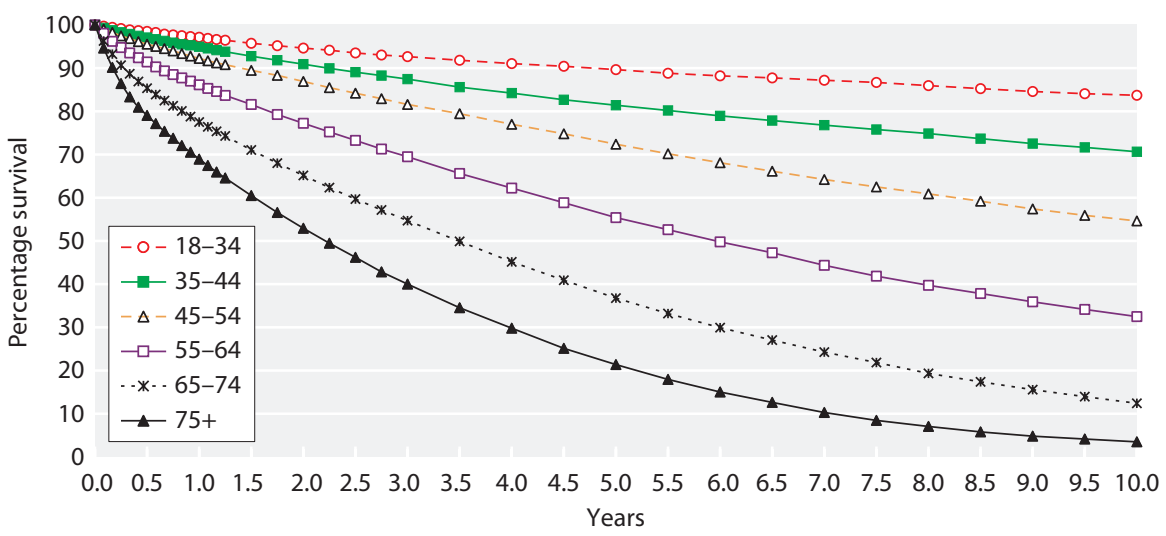

Fig. 5.4. Survival of incident RRT patients (unadjusted), 1997-2014 cohort (from day 0) 

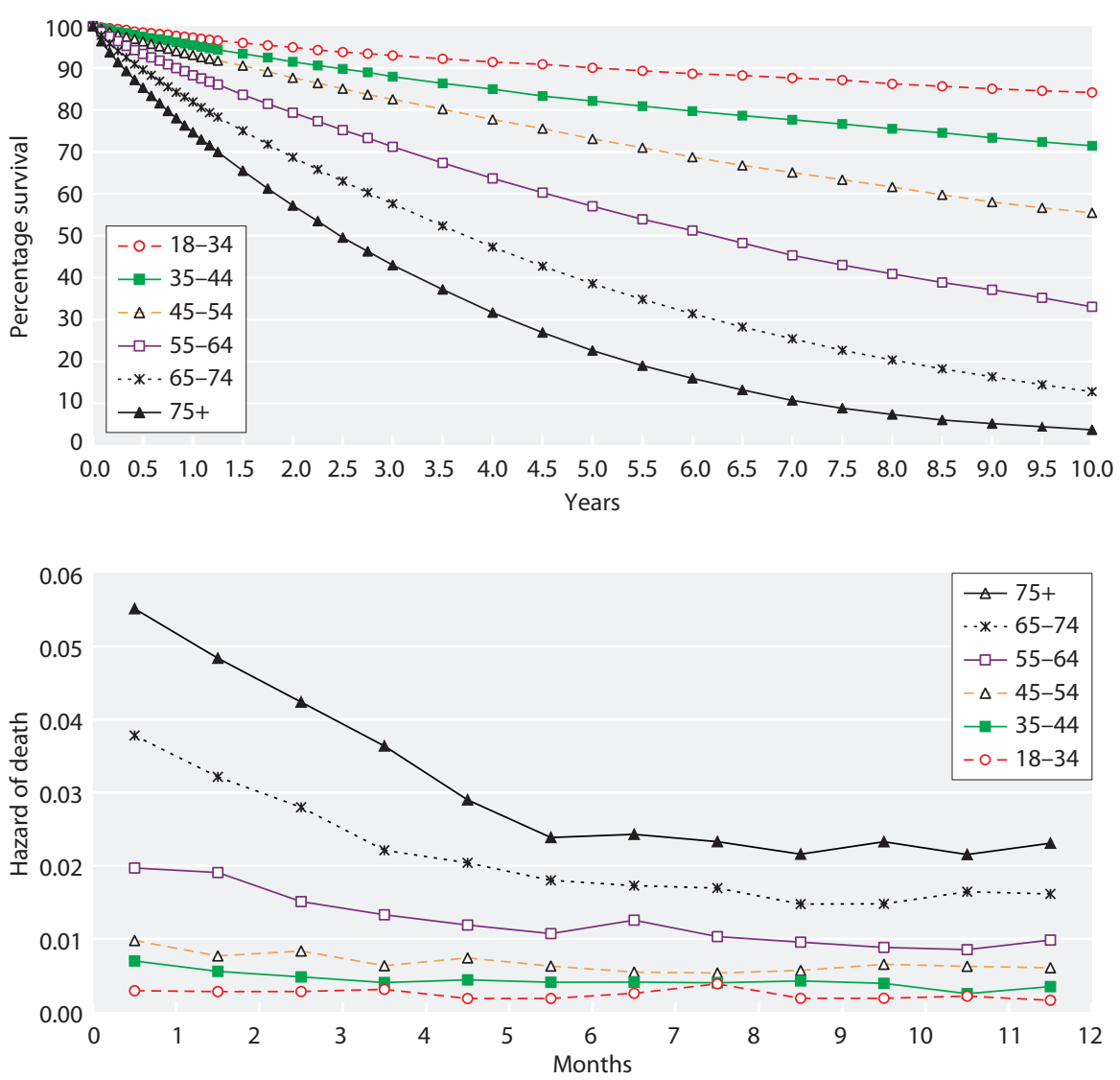

Fig. 5.5. Survival of incident RRT patients (unadjusted), 1997-2014 cohort (from day 90)
Fig. 5.6. First year monthly hazard of death, by age group, 1997-2014 combined incident RRT cohort respectively. This difference in survival becomes less pronounced with increasing age, especially for patients aged $65+$. This was previously examined in more detail in the 2008 Annual Report [9].

\section{Age and the hazard of death}

Figure 5.6 shows the monthly hazard of death from the first day of starting RRT by age group, which falls sharply during the first 4-5 months, particularly for older patients ( $\geqslant 65$ years), after which time the hazard remains relatively stable up to one year.

The hazard of death at 90 days per 10 year increase in patient age fell from 1.85 in the 2013 cohort to 1.61 (2014 cohort) while the hazard in the 1st year after 90 days also fell, but by a lesser magnitude (1.59 in the 2014 cohort compared to 1.65 in the 2013 cohort) (table 5.6).

\section{Survival by gender}

There was no survival difference between genders in the incident RRT cohort of patients starting RRT from 2003 to 2012 and followed up for a minimum of three years until 2015 (figure 5.7). There was also no evidence of a survival difference between genders in the first 90 days and one year after the first 90 days (data not shown).

\section{Survival in the 2005-2014 cohort}

The death rate per 1,000 patient years in the first year of starting RRT from 2005 to 2014 is shown in figure 5.8. There was essentially no change in the death rate from 2013 to 2014 on a background of a declining trend in the death rate overall and over the past decade, but with a more marked fall in the older age group $(\geqslant 65$ years). It is important to note that these death rates may not be directly comparable with those produced by other registries (for instance the USRDS) if the first 90 day period, when death rates are higher than subsequent time periods, are excluded.

The time trend changes in one year after 90 days incident survival over the period 2005-2014 are shown in figure 5.9. The left hand plot, which includes only those

Table 5.6. Increase in proportional hazard of death for each 10 year increase in age, 2014 incident RRT cohort

\begin{tabular}{|c|c|c|}
\hline Interval & $\begin{array}{l}\text { Hazard of death for } \\
10 \text { year age increase }\end{array}$ & $95 \% C I$ \\
\hline First 90 days & 1.61 & $1.47-1.76$ \\
\hline 1 year after first 90 days & 1.59 & $1.51-1.68$ \\
\hline
\end{tabular}




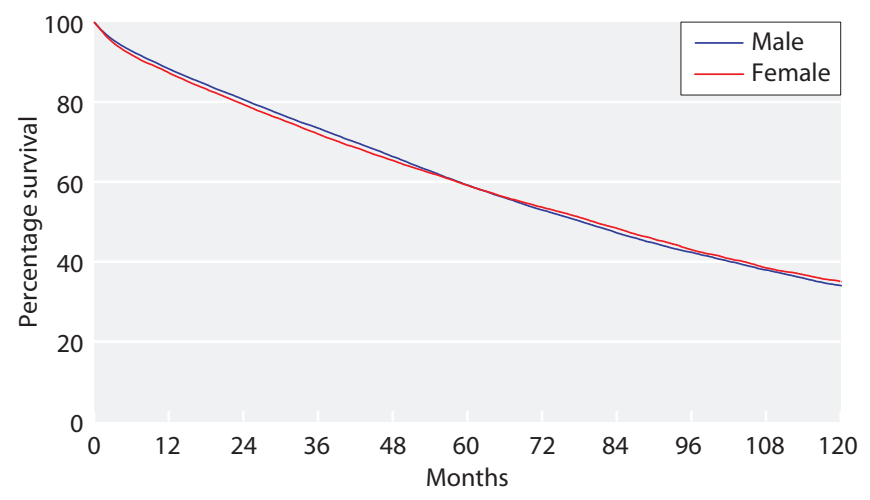

Fig. 5.7. Long term survival of incident RRT patients by gender, 2003-2012 combined cohort, adjusted to age 60, followed-up for a minimum of three years

centres that have been sending data continuously since the year 2000, shows a similar survival trend to the plot in which data from all renal centres were analysed, namely that the percentage of patients surviving one year after 90 days has fallen slightly in 2014 compared with the preceding year (from $91.4 \%$ to $90.2 \%$ for all renal centres).

One year after 90 days incident RRT patient survival in the 2005-2014 cohort by centre, UK country and overall, can be found in appendix 1, table 5.22.

\section{Long term survival: trends up to 10 years post RRT start}

The unadjusted survival analyses (tables 5.7, 5.8 and figures 5.10, 5.11) show an overall improvement in longer term survival between 1998 and 2014 for both those aged $<65$ years and those $\geqslant 65$ years. For example, five year survival amongst patients aged $<65$ years at start of RRT has improved from $64.1 \%$ in the 1998 cohort to $72.8 \%$ in the 2010 cohort. For those aged 65 years and above at RRT initiation during the same period, five

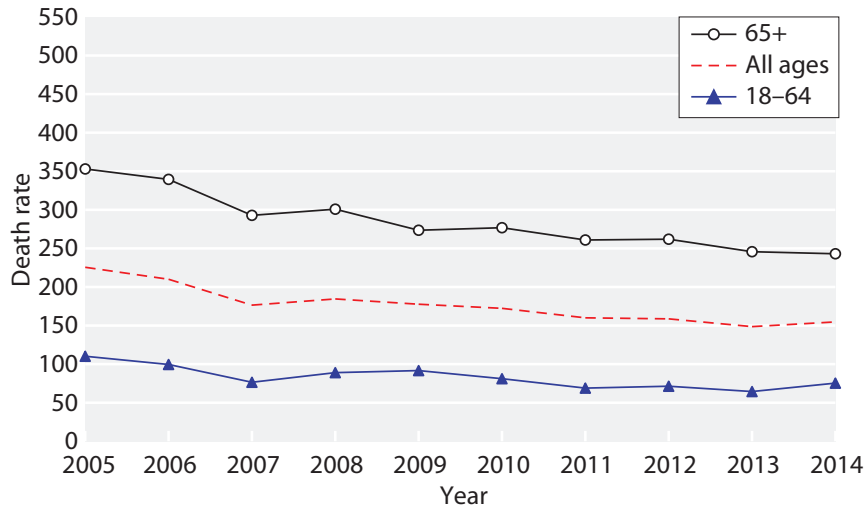

Fig. 5.8. One year incident RRT death rate per 1,000 patient years by age group, 2005-2014 cohort

year survival improved from $20.0 \%$ (1998) to $32.5 \%$ (2010).

Although survival improved overall between the 1998 and 2014 cohorts, the improvement was more pronounced in patients aged $\geqslant 65$ : there has been a $16.1 \%$ absolute improvement in one year survival from the 1998 to 2014 cohorts (table 5.8), versus 5.2\% in those $<65$ years during the same period. It is not possible to ascertain the specific reasons for this reduction in risk of death.

\section{Survival by $R R T$ vintage}

Figure 5.12 shows the six monthly hazard of death for incident patients, by age group. There is little evidence of a worsening prognosis with increasing time on RRT (vintage) for the majority of incident RRT patients in the UK, except in incident patients aged 65 years and older where an increased hazard over time is evident. When the analysis is repeated with censoring for transplantation an apparent vintage effect is evident (data not shown) and this is, at least in part, because younger and healthier patients are only included in the survival

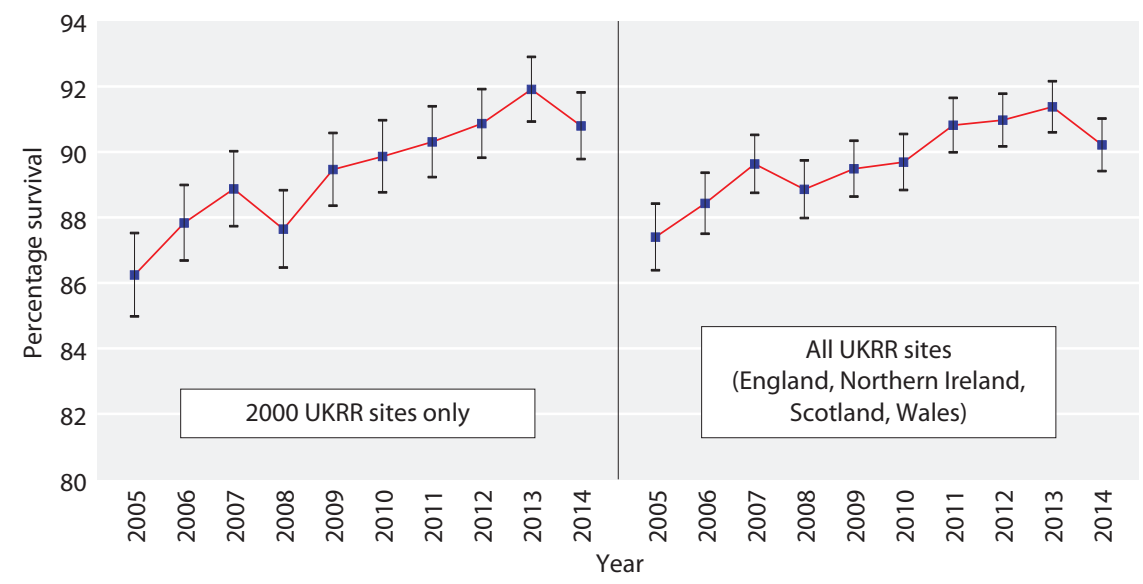

Fig. 5.9. Change in one year after 90 day survival, 2005-2014 incident RRT cohort (adjusted to age 60) Showing $95 \%$ confidence intervals 
Table 5.7. Unadjusted survival of incident RRT patients, 1998-2014 cohort for patients aged 18-64 years

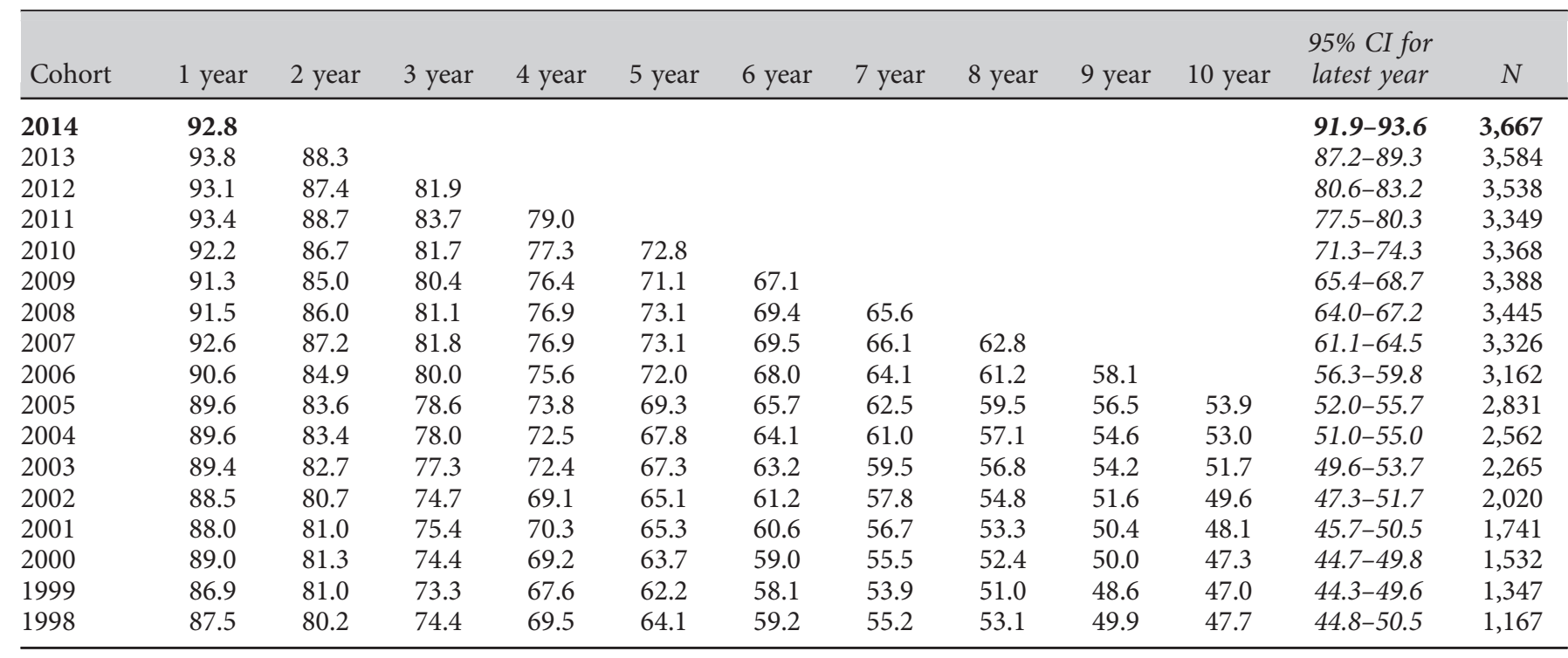

Table 5.8. Unadjusted survival of incident RRT patients, $1998-2014$ cohort for patients aged $\geqslant 65$ years

\begin{tabular}{|c|c|c|c|c|c|c|c|c|c|c|c|c|}
\hline Cohort & 1 year & 2 year & 3 year & 4 year & 5 year & 6 year & 7 year & 8 year & 9 year & 10 year & $\begin{array}{l}95 \% \text { CI for } \\
\text { latest year }\end{array}$ & $N$ \\
\hline 2014 & 78.6 & & & & & & & & & & $77.3-79.9$ & 3,584 \\
\hline 2013 & 78.5 & 64.6 & & & & & & & & & $63.0-66.2$ & 3,439 \\
\hline 2012 & 77.3 & 65.3 & 54.4 & & & & & & & & $52.7-56.1$ & 3,333 \\
\hline 2011 & 77.4 & 62.8 & 51.4 & 41.1 & & & & & & & $39.4-42.8$ & 3,361 \\
\hline 2010 & 76.3 & 63.4 & 51.2 & 42.0 & 32.5 & & & & & & $30.8-34.1$ & 3,280 \\
\hline 2009 & 76.5 & 63.2 & 52.5 & 41.5 & 32.9 & 26.1 & & & & & $24.6-27.6$ & 3,374 \\
\hline 2008 & 74.5 & 61.1 & 49.8 & 40.4 & 32.2 & 25.7 & 20.5 & & & & $19.1-22.0$ & 3,175 \\
\hline 2007 & 75.0 & 61.1 & 49.7 & 40.4 & 31.9 & 25.3 & 20.1 & 15.5 & & & $14.2-16.8$ & 3,211 \\
\hline 2006 & 72.0 & 58.3 & 46.9 & 37.3 & 29.0 & 23.1 & 17.7 & 13.4 & 10.7 & & $9.6-11.9$ & 3,116 \\
\hline 2005 & 71.1 & 57.2 & 45.3 & 36.2 & 27.9 & 21.2 & 16.6 & 12.5 & 10.0 & 7.8 & $6.9-8.8$ & 2,940 \\
\hline 2004 & 69.0 & 54.0 & 42.4 & 34.1 & 26.9 & 21.1 & 16.5 & 13.0 & 9.9 & 7.6 & $6.7-8.7$ & 2,632 \\
\hline 2003 & 68.4 & 53.6 & 41.7 & 31.8 & 24.3 & 18.1 & 14.3 & 11.1 & 8.5 & 6.8 & $5.8-7.9$ & 2,318 \\
\hline 2002 & 66.0 & 50.8 & 40.3 & 31.8 & 23.8 & 18.3 & 13.7 & 10.9 & 8.2 & 6.5 & $5.5-7.6$ & 2,089 \\
\hline 2001 & 66.5 & 51.7 & 38.3 & 28.7 & 21.7 & 15.9 & 11.8 & 8.9 & 7.1 & 5.5 & $4.4-6.6$ & 1,708 \\
\hline 2000 & 66.1 & 52.4 & 39.6 & 28.6 & 22.3 & 17.2 & 13.1 & 9.7 & 7.5 & 5.7 & $4.6-7.0$ & 1,496 \\
\hline 1999 & 68.3 & 51.5 & 39.0 & 29.8 & 22.2 & 16.1 & 11.5 & 8.3 & 6.1 & 4.8 & $3.7-6.1$ & 1,214 \\
\hline 1998 & 62.5 & 45.3 & 35.9 & 26.3 & 20.0 & 13.9 & 10.5 & 7.5 & 5.7 & 4.6 & $3.5-6.1$ & 1,016 \\
\hline
\end{tabular}

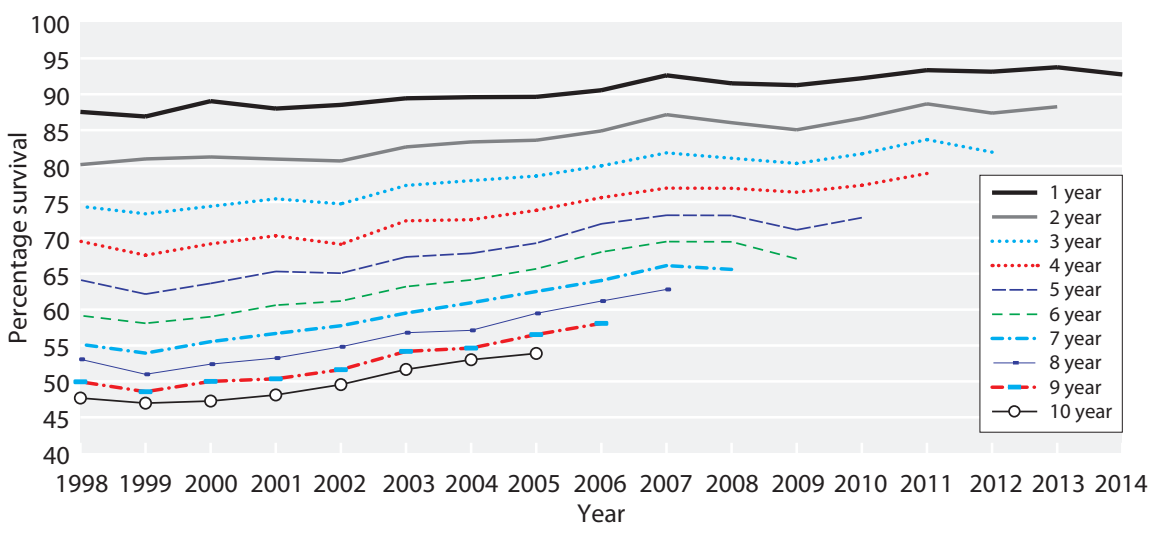

Fig. 5.10. Change in long term survival by year of starting RRT (1998-2014), for incident RRT patients aged 18-64 years 

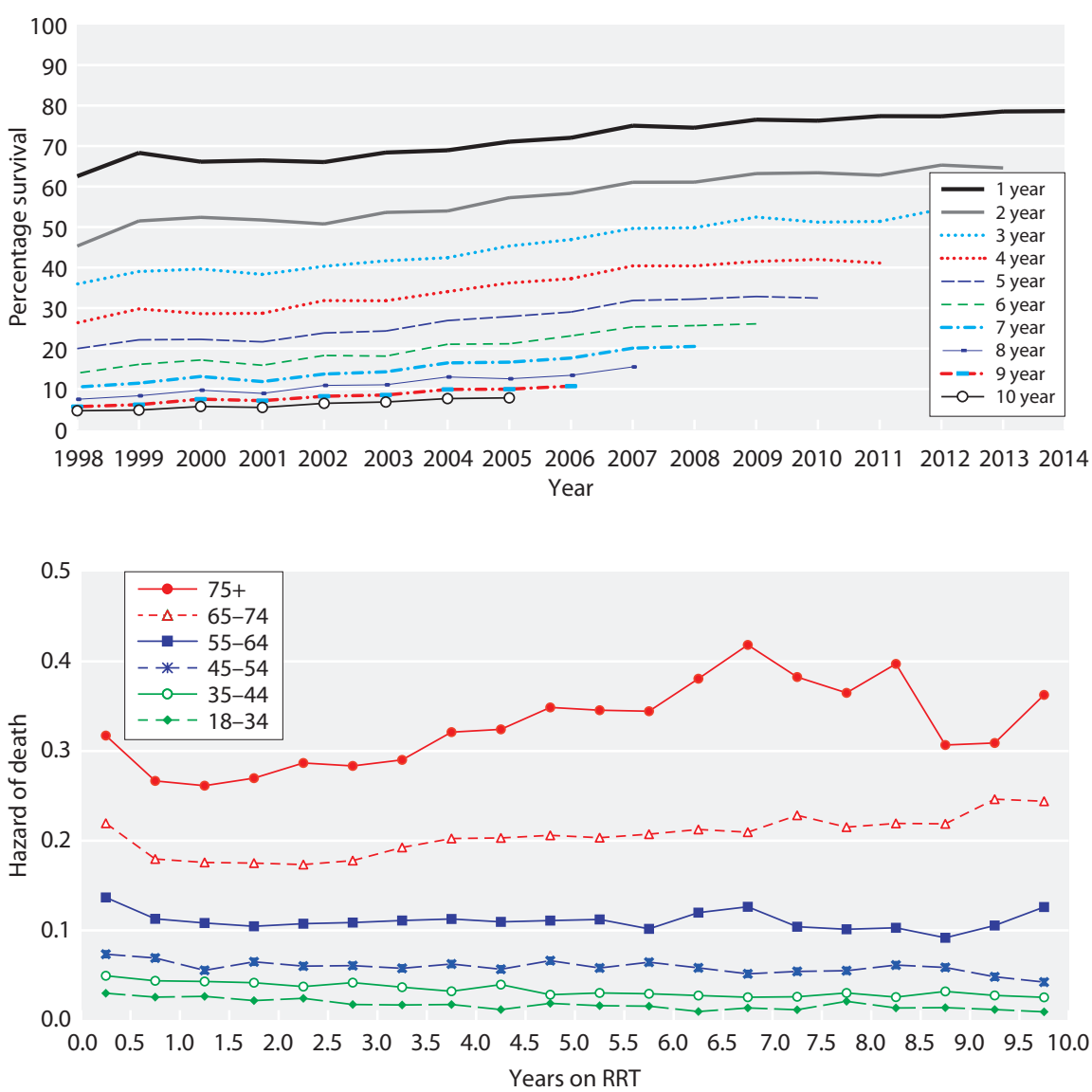

Fig. 5.11. Change in long term survival by year of starting RRT (1998-2014), for incident RRT patients aged $\geqslant 65$ years
Fig. 5.12. Six monthly hazard of death, by vintage and age group, 1997-2014 incident RRT cohort after day 90 calculation up to the date of transplantation. In the oldest age group, the number of patients surviving beyond seven years was small, accounting for the variability seen. Figures 5.13 and 5.14 show the same analysis for patients without diabetes and with diabetes respectively. An increased hazard of death over time is evident for patients with diabetes predominantly $\geqslant 65$ years of age.

Centre variability in one year after 90 days survival

Due to small numbers of incident patients in any given year in each centre and resultant wide confidence intervals, variability by renal centre was assessed in a larger cohort across several years. Similar to previous years, sustained performance was assessed in a rolling four year cohort from 2011 to 2014. These data are presented as a funnel plot in figure 5.15. Table 5.9 allows centres to be identified on this graph by finding the number of patients treated by the centre and then looking up the corresponding number on the $\mathrm{x}$-axis. Two centres (Cardiff and Swansea) had survival below the 95\% lower limit whilst three centres (Aberdeen, London Guy's, Reading) had survival above the 95\% upper limit. This

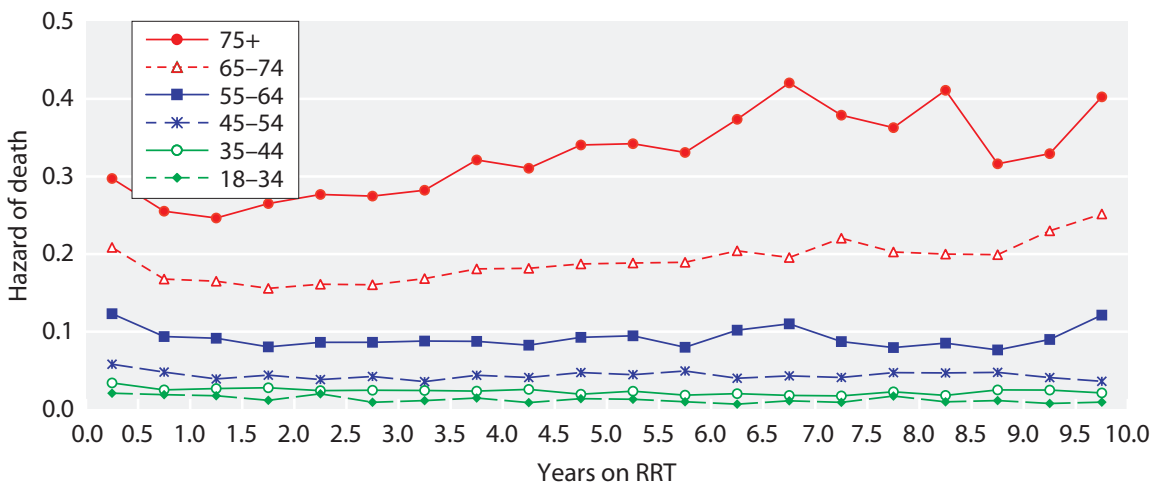

Fig. 5.13. Six monthly hazard of death, by vintage and age group, 1997-2014 incident RRT cohort without diabetes after day 90 


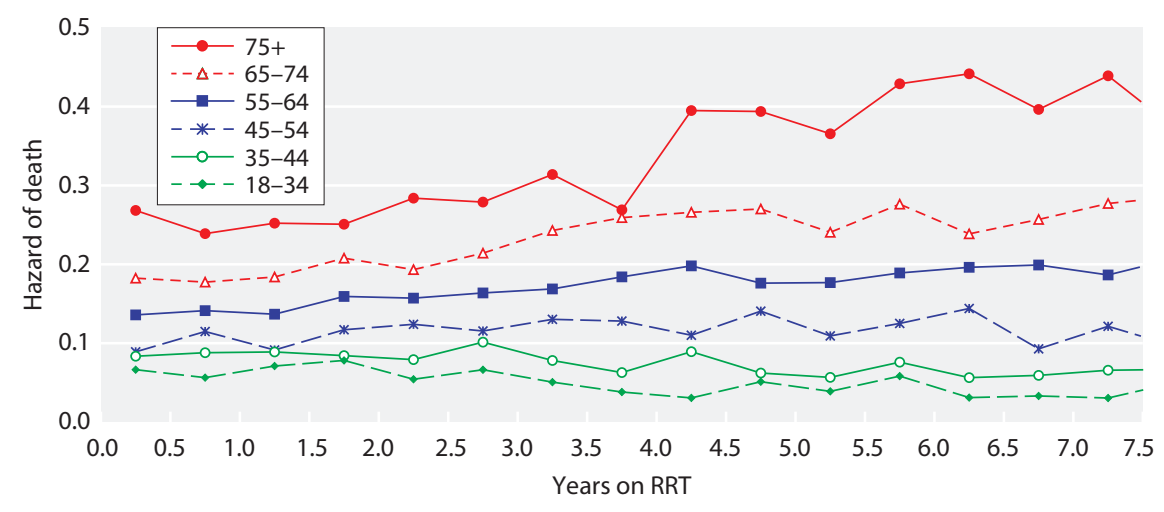

Fig. 5.14. Six monthly hazard of death, by vintage and age group, 1997-2014 incident RRT cohort with diabetes after day 90 is compared with last year when five centres were survival outliers above the 95\% upper limit. With 71 centres included in the analysis it would be expected that three centres would be outside these limits by chance. It is important to highlight that these data have only been adjusted for age (i.e. no other patient factors such as comorbidity, primary renal disease or ethnicity) and have not been censored at transplantation. Therefore the effect of differing rates of transplantation by centre was not taken into account. Please see the following section for the effects of adjustment for primary renal disease and comorbidity.

Appendix 1 contains additional tables related to these survival analyses; tables 5.22 and 5.23 show unadjusted and adjusted survival together with $95 \%$ confidence intervals for incident patient survival one year after 90 days and at 90 days for the 2014 single year cohort. Table 5.24 in appendix 1 shows the one year after 90 day incident survival by centre for incident RRT cohort years 2005-2014, adjusted to age 60. One to five year survival after the first 90 days of RRT adjusted to age 60 is included in appendix 1 , table 5.25 for incident RRT cohorts 2010-2014.

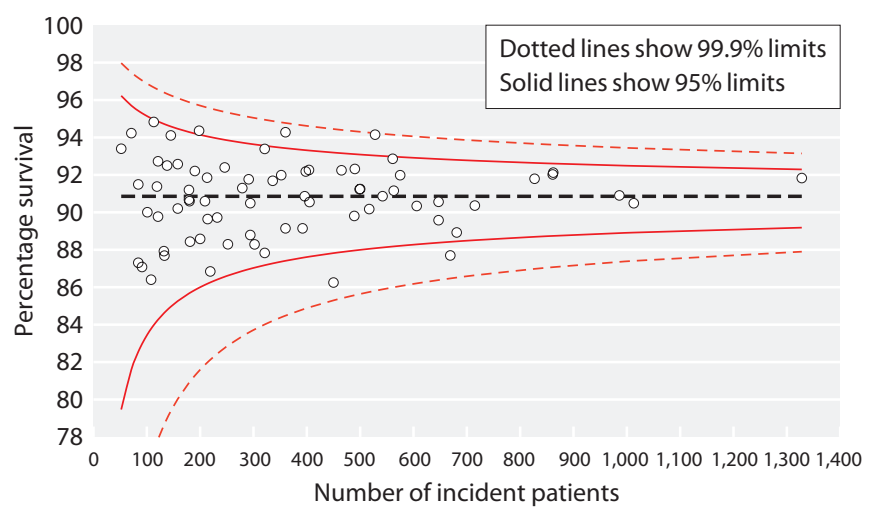

Fig. 5.15. Funnel plot for age adjusted one year after 90 days survival, 2011-2014 incident RRT cohort
Centre variability in one year after 90 day survival: impact of adjustment for comorbidity

Although comorbidity returns to the UKRR have remained poor, some centres have consistently returned $\geqslant 85 \%$ comorbidity data for incident patients. The analyses in this section use a combined incident RRT cohort from 2011-2014 for the 28 centres who consistently returned comorbidity data for $\geqslant 85 \%$ of patients during this period, and demonstrate the impact of sequential adjustment for age, primary renal diagnosis and comorbidity (table 5.10 ).

It can be seen that adjustment for age has the largest effect, most notably in those centres with the lower unadjusted survival figures. Survival improved for all centres after adjustment for age, as the average age for incident patients was higher than the adjustment to age 60 years. There were only minor changes in survival for most centres after adjustment for primary renal diagnosis, but survival did increase by $\geqslant 1 \%$ for three centres (Newry, Swansea, Wolverhampton). In two centres (Newcastle, Swansea) adjustment for comorbidity had a noticeable effect ( $\geqslant 1 \%$ increase) on adjusted survival (table 5.10, figure 5.16). After adjustment for age, primary renal diagnosis and comorbidity, Swansea, Antrim, Wrexham and Ulster had the largest improvement in survival of $9.4 \%, 8.7 \%, 7.0 \%$ and $6.9 \%$ respectively.

The largest survival improvement, as a result of adjustment for comorbidity was seen in Swansea. Adjustment for comorbidity may have an important differential effect for renal centres that have a higher comorbid burden in their RRT population. This could affect the status of centres as a survival outlier as shown in figure 5.15, such as Swansea or Cardiff. However due to poor comorbidity returns for many renal centres, comorbidity adjustment for the entire incident RRT population is not yet possible. Data completeness and data quality both have significant implications for the accuracy of analyses

Nephron 2017;137(suppl1):117-150 
Table 5.9. Age adjusted (to age 60) one year after 90 day survival, 2011-2014 incident RRT cohort

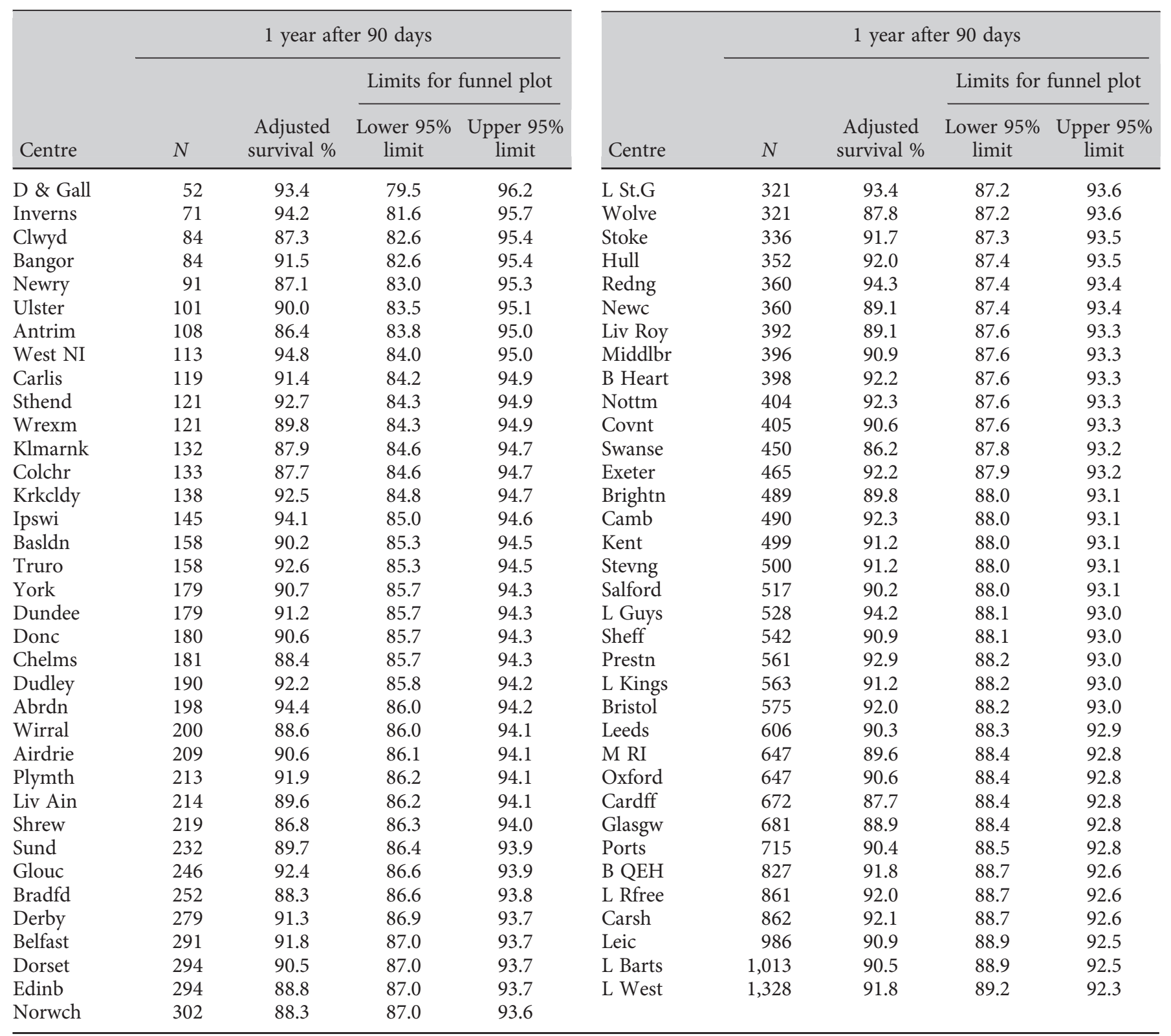

such as these. Case mix adjustment performed in a cohort of incident patients starting RRT in England from 2002 to 2006 which was linked to the Hospital Episodes Statistics (HES) data, found that three of the four survival outliers at that time were no longer outliers after adjustment for HES-derived case mix. Swansea and Cardiff could not be evaluated in that analysis as HES only included English hospitals, but the study results highlight that observed variability in survival between centres is affected by case mix [10].

\section{Survival in patients with diabetes}

Patients with diabetes have been shown to have worse long term survival compared to patients without diabetes [3]. In the following analyses, 90 day survival, 1 year after 90 day survival and long term survival are presented according to the presence or absence of a diagnosis of diabetes.

In the UK in 2014, 90 day survival for incident patients with diabetes was better than those without diabetes across the age categories of 18-44 years, 45-64 years 
Table 5.10. The effect of adjustment for age, primary renal diagnosis and comorbidity on survival, 2011-2014 incident RRT cohort, percentage survival one year after 90 days

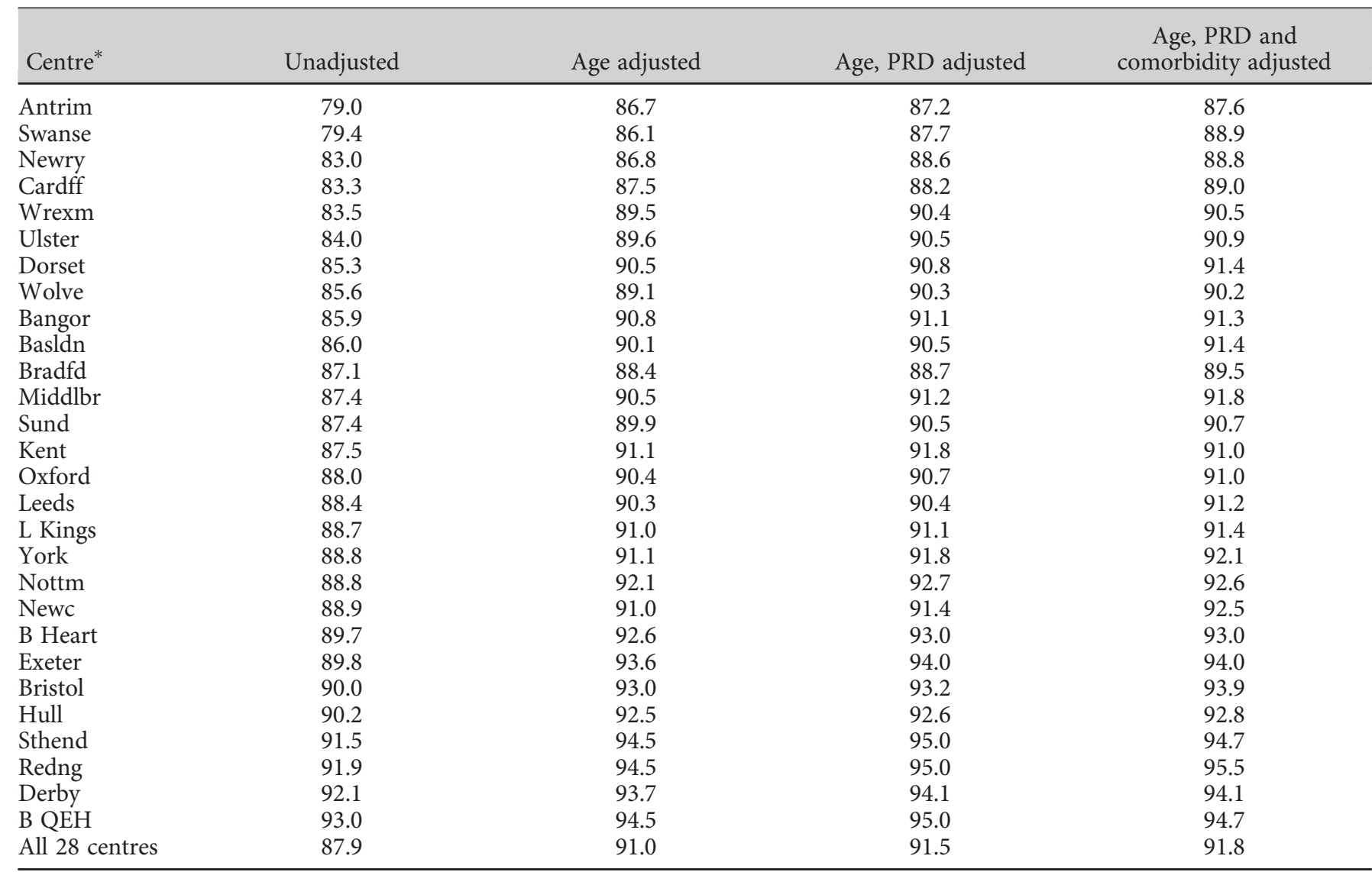

PRD primary renal diagnosis

${ }^{*}$ Centre included if $\geqslant 85 \%$ comorbidity data available

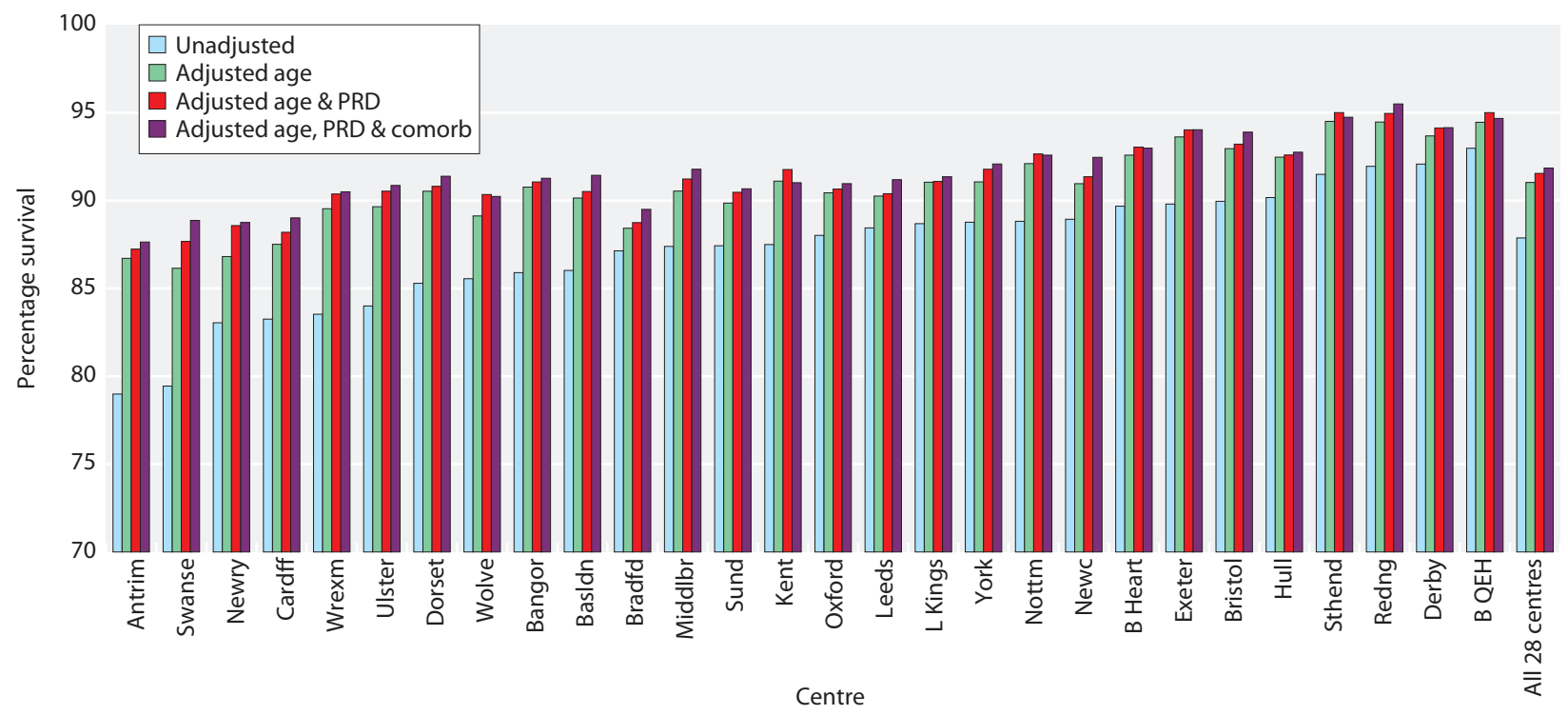

Fig. 5.16. The effect on one year after 90 day survival after sequential adjustment for age, primary renal diagnosis and comorbidity, 2011-2014 incident RRT cohort 


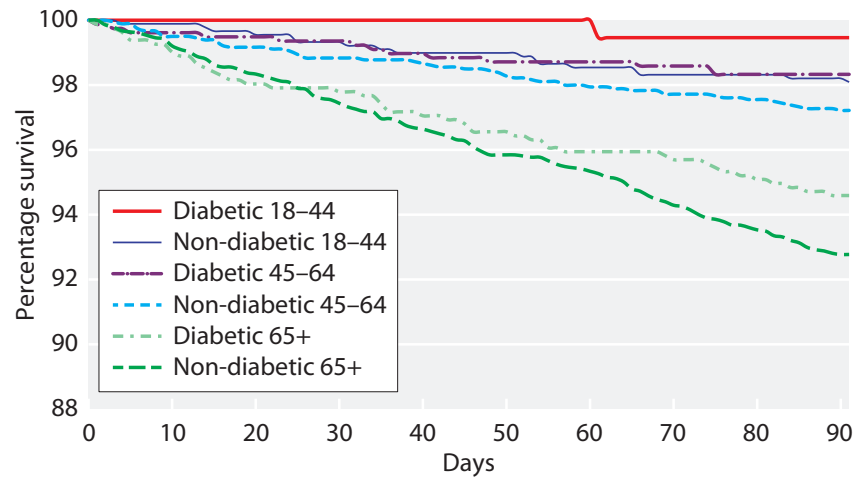

Fig. 5.17. Survival at 90 days for incident RRT patients with and without diabetes by age group, 2014 cohort

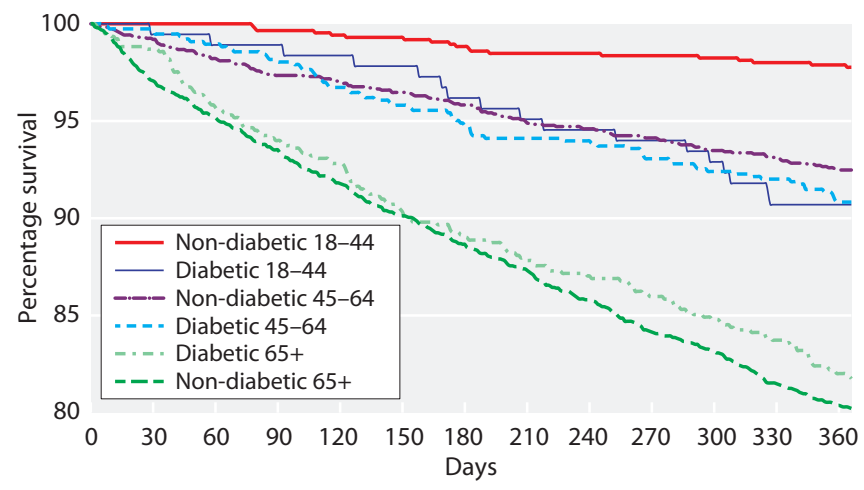

Fig. 5.18. Survival at one year after 90 days for incident RRT patients with and without diabetes by age group, 2014 cohort

and 65 years and over (figure 5.17). For one year survival after 90 days in the 2014 cohort, young patients (18-44 years) without diabetes had better survival than their counterparts with diabetes, whereas for the 45-64 years group and those 65 years and over, the survival was more similar (figure 5.18).

Long term survival for patients with diabetes and patients without diabetes is presented for the incident RRT cohort of patients starting RRT from 2003 to 2012 with a minimum of three years follow up (figure 5.19). These data show large differences between survival for

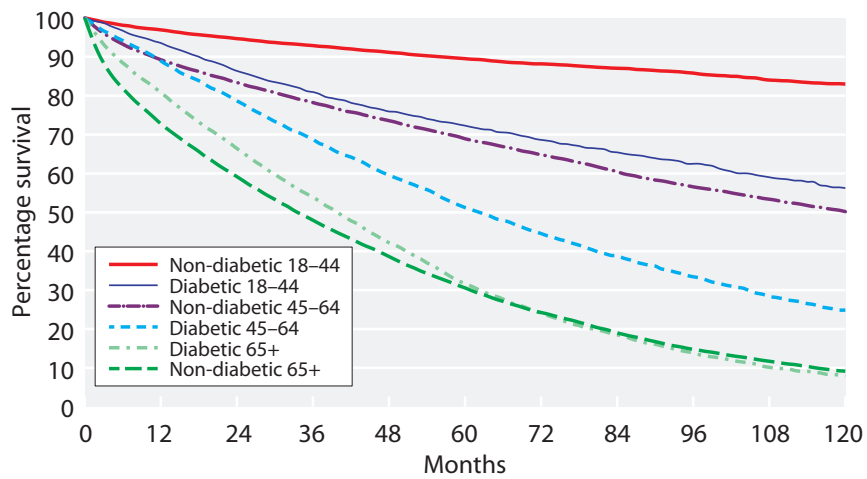

Fig. 5.19. Long term survival for incident RRT patients with and without diabetes by age group, 2003-2012 cohort, followed up for a minimum of three years

those with diabetes and those without diabetes in the age groups 18-44 years and 45-64 years. In the age group $18-44$ years, $89.5 \%$ of patients without diabetes were alive five years after start of RRT compared to $72.3 \%$ for patients with diabetes. In the age group 45 64 years, $68.9 \%$ of patients without diabetes were alive five years after start of RRT compared to $51.2 \%$ for patients with diabetes (figure 5.19). The initial survival difference where incident RRT patients without diabetes in the older age group ( $\geqslant 65$ years) had poorer survival than incident patients with diabetes in the same age group, diminished over the years until there was very little difference in five year survival between these groups.

\section{Survival in prevalent dialysis patients}

\section{Overall survival}

Table 5.11 shows the one and two year survival for prevalent patients on dialysis. One year age adjusted survival for prevalent dialysis patients was essentially stable at $88.3 \%$ in the 2014 cohort compared to $88.6 \%$ in the 2013 cohort. Two year survival dropped slightly from $72.1 \%$ to $71.1 \%$.

Table 5.11. One and two year survival of prevalent dialysis patients

\begin{tabular}{lcccc}
\hline & Patients & Deaths & Survival \\
Patient group & $N$ & $N$ & & $95 \%$ CI \\
\hline 1 year survival - 2014 cohort & & & 84.4 & $84.0-84.9$ \\
Unadjusted & 26,437 & 3,955 & 88.3 & $87.8-88.7$ \\
Adjusted to age 60 & 26,437 & 3,955 & 71.1 & $70.5-71.7$ \\
2 year survival - 2013 cohort & & & 6,956 & \\
Unadjusted & 26,130 & & \\
\hline
\end{tabular}

2014 cohort: all dialysis patients alive on $31 / 12 / 2014$

2013 cohort: all dialysis patients alive on $31 / 12 / 2013$ 
Table 5.12. One year death rate per 1,000 prevalent dialysis patient years in the 2014 cohort and median age of prevalent dialysis patients by UK country

\begin{tabular}{lcccc}
\hline & England & N Ireland & Scotland & Wales \\
\hline Death rate & 166 & 167 & 188 & 217 \\
95\% CI & $160-172$ & $136-203$ & $168-210$ & $190-247$ \\
Median age & 67.0 & 70.5 & 66.2 & 69.0 \\
\hline
\end{tabular}

\section{Survival by UK country}

The one year death rate for prevalent dialysis patients in 2014 for each UK country is shown in table 5.12. The death rate rose in every UK nation compared to the 2013 cohort, except in Northern Ireland, with the median age of prevalent dialysis patients increasing in all four nations. The one year unadjusted death rate in Wales was significantly higher than in England. However, the higher median age in Wales and socio-economic factors such as general population life expectancy and area deprivation, may contribute to the death rate in Wales. These results are unadjusted for age, primary renal diagnosis or comorbidity.

\section{One year survival of prevalent dialysis patients}

by centre

The age adjusted (adjusted to age 60) one year survival of dialysis patients by centre is illustrated in a funnel plot (figure 5.20). As there are 71 centres included in the analyses, it would be expected that three centres would fall outside the $95 \%$ ( 1 in 20) confidence limits, entirely by chance. The survival for patients attending two centres (Oxford and Manchester Royal Infirmary) was below the 95\% confidence limit, and there were no centres below the $99 \%$ confidence limit. Comparing data over a number of years, there is no centre that has consistently been below the 95\% confidence limits. One centre (West

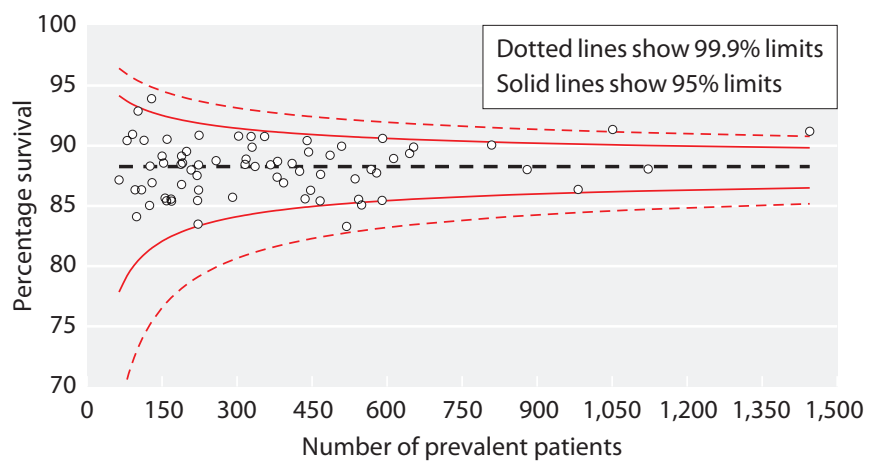

Fig. 5.20. One year survival funnel plot of prevalent dialysis patients by centre adjusted to age 60,2014 cohort
Northern Ireland) was above the 95\% confidence limits, and two centres (London West and Birmingham Queen Elizabeth) were above the $99 \%$ confidence limit. A sensitivity analysis was performed, without censoring at transplantation, and the results for outlying centres were unchanged. These observed differences may have occurred by chance, may be true differences or may reflect differences in the case-mix of the renal centres. For incident patient survival, incomplete comorbidity returns prevent full adjustment for case mix.

Table 5.13 allows centres in figure 5.20 to be identified by finding the number of patients treated by the centre and the corresponding survival and then looking this up on the axes of the funnel plot.

One year survival of dialysis patients by centre is illustrated in figures 5.21 and 5.22 for patients aged $<65$ years and those aged $\geqslant 65$ years.

\section{Survival by age group}

Figure 5.23 shows the one year survival of prevalent dialysis patients who were alive and receiving dialysis on 31st December 2014, stratified by age group. This demonstrates a curvilinear decrease in survival with increasing age.

\section{One year death rate in prevalent dialysis patients by} age group, 2014 cohort

The death rates for prevalent patients on dialysis by age group are shown in figure 5.24. The younger patients included in this analysis are a selected higher risk group, as they remained on dialysis rather than undergoing transplantation. The increase in the death rate with age was not linear; in those aged $<45$ years, a 10 year increase in age was associated with a rise in the death rate of approximately 25 deaths per 1,000 patient years compared with those $\geqslant 75$ years where a 10 year increase in age was associated with a rise of about 100 deaths per 1,000 patient years.

\section{Time trends in survival, 2005 to 2014}

Figure 5.25 illustrates that one year survival for prevalent dialysis patients in England gradually improved from 2005 to 2011 with a gradual decrease thereafter. The numbers of patients were smaller in Scotland, Northern Ireland and Wales which resulted in variability and wide confidence intervals, so no firm conclusions can be drawn. The change in prevalent survival by centre between 2005 to 2014 is included in appendix 1, table 5.26. 
Table 5.13. One year survival of prevalent dialysis patients in each centre (adjusted to age 60), 2014 cohort

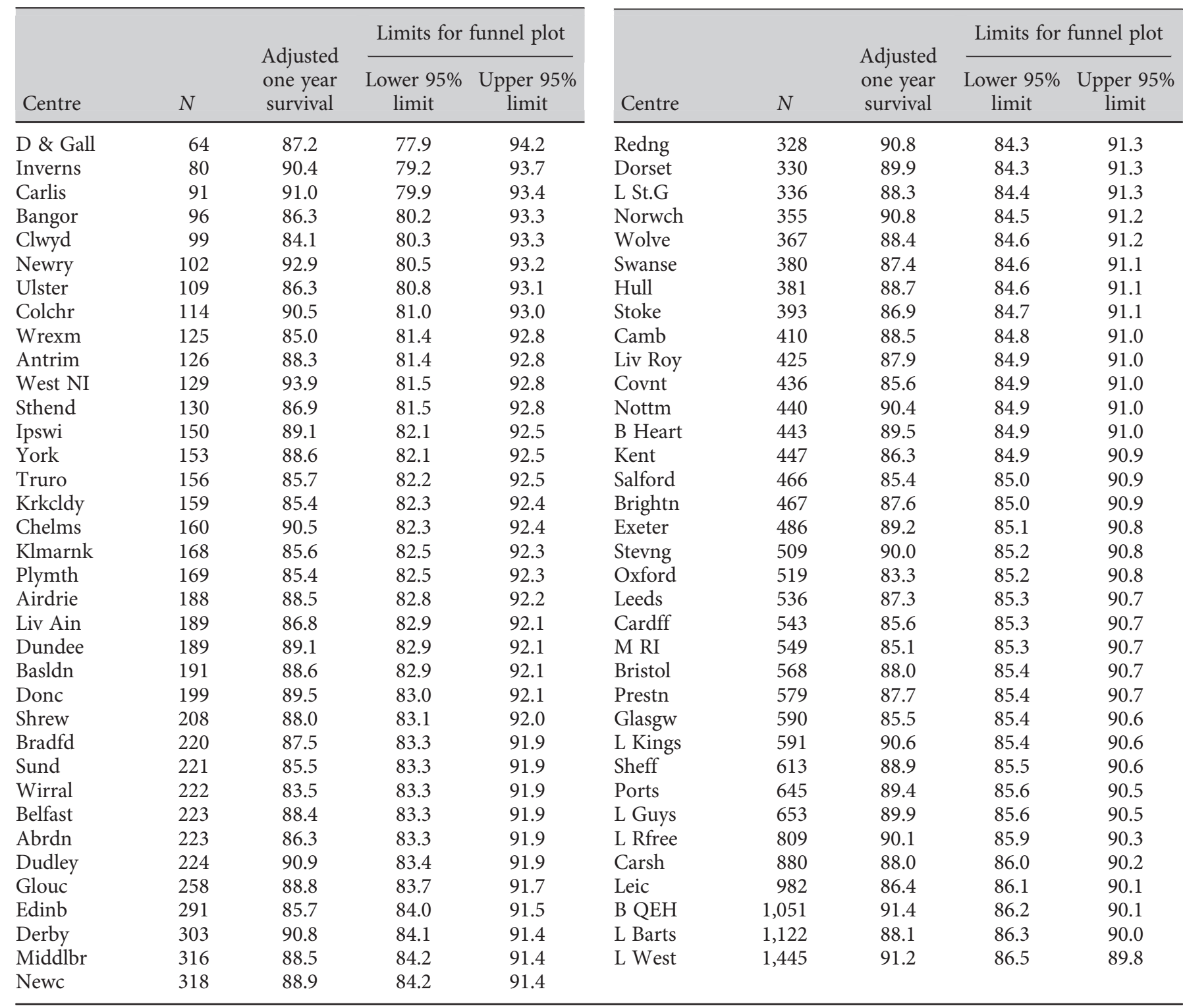

\section{Survival in prevalent dialysis patients with diabetes}

In patients aged $<65$ years, one year survival for prevalent dialysis patients with diabetes was $8.1 \%$ lower compared to the same age group without diabetes. In contrast, for prevalent dialysis patients aged $65+$ years, survival was very similar for those with and without diabetes (only $1 \%$ lower, table 5.14 ).

Time trends in patients with a primary diagnosis of diabetes

The age adjusted one year survival for prevalent dialysis patients with a reported primary renal disease of diabetic nephropathy are shown in table 5.15.

\section{Death rate on RRT compared with the UK general population}

The death rate of patients on all RRT modalities compared to the general population is shown in table 5.16. The relative risk of death on RRT decreased with age from a peak of more than 30 times that of the general population at age 25-29 years to 2.3 times the general population at age 85 and over. Figure 5.26 shows that the relative risk of death has decreased substantially for the younger age groups ( $<50$ years $)$ in recent years, whereas the relative risk of death in patients aged over 55 has not changed greatly in the 2014 cohort compared 


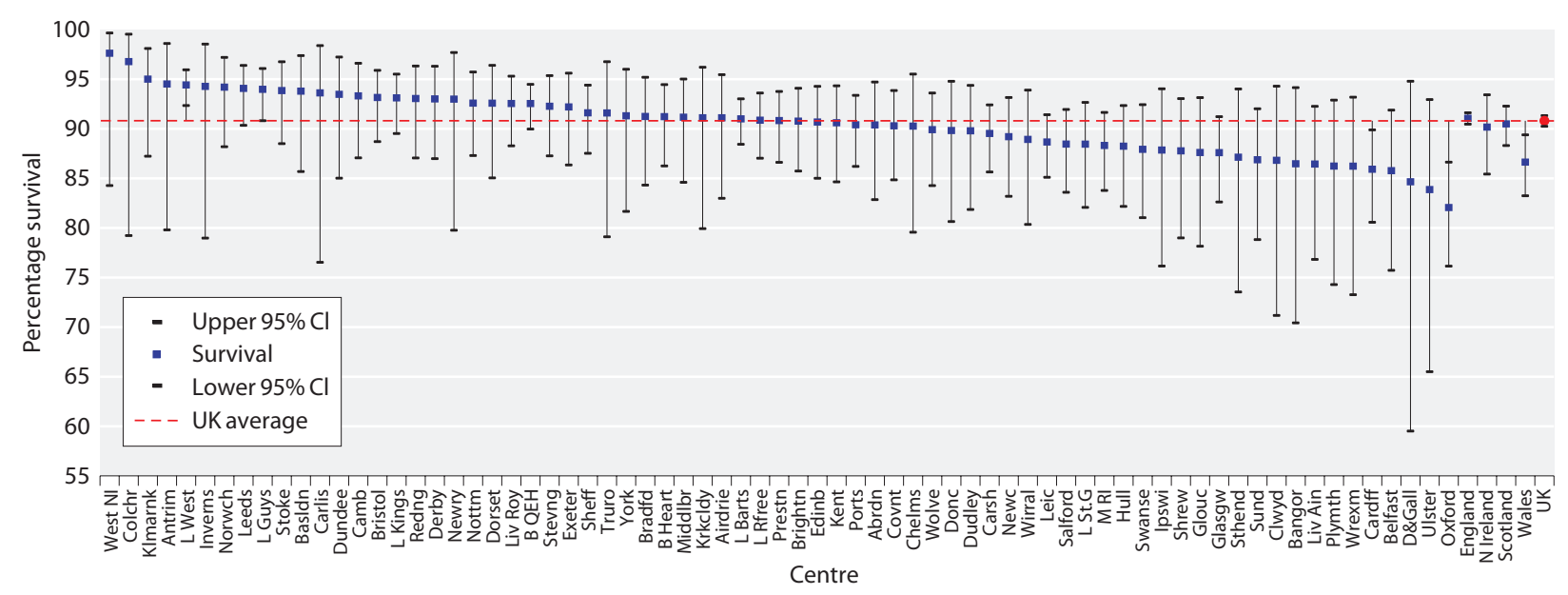

Fig. 5.21. One year survival of prevalent dialysis patients aged under 65 years by centre, 2014 cohort

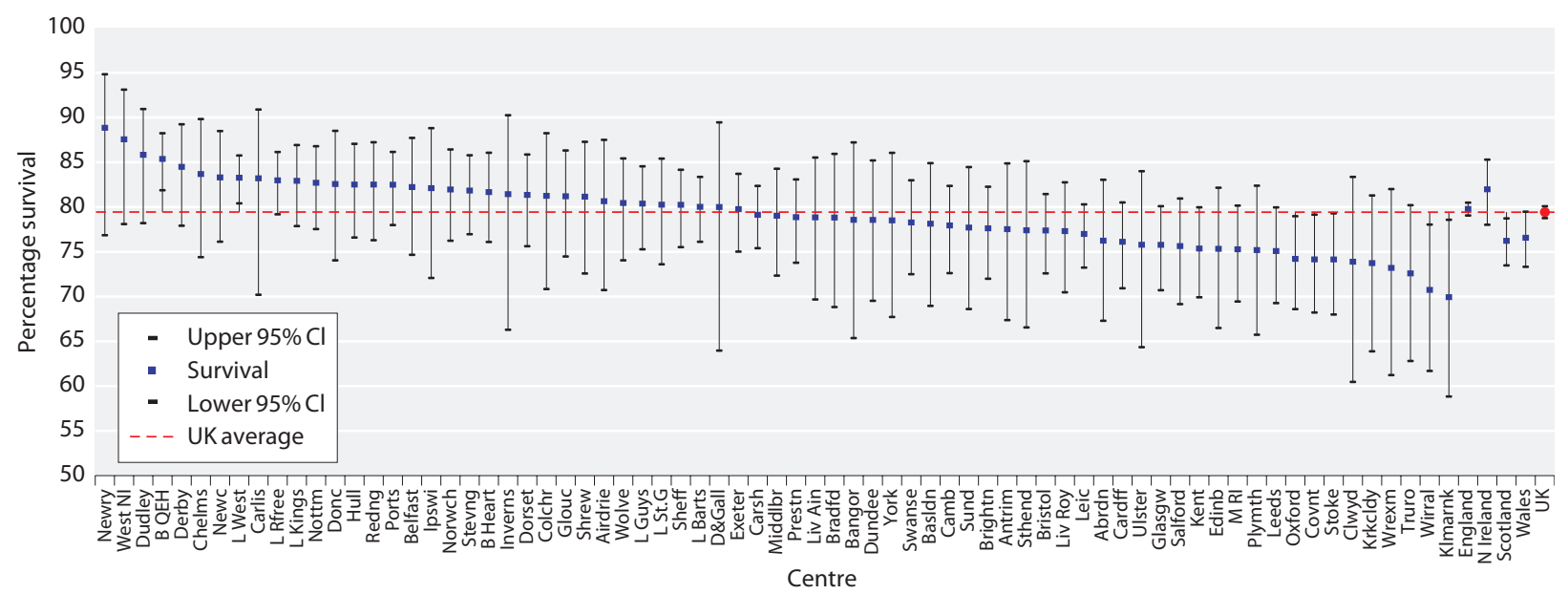

Fig. 5.22. One year survival of prevalent dialysis patients aged 65 years and over by centre, 2014 cohort

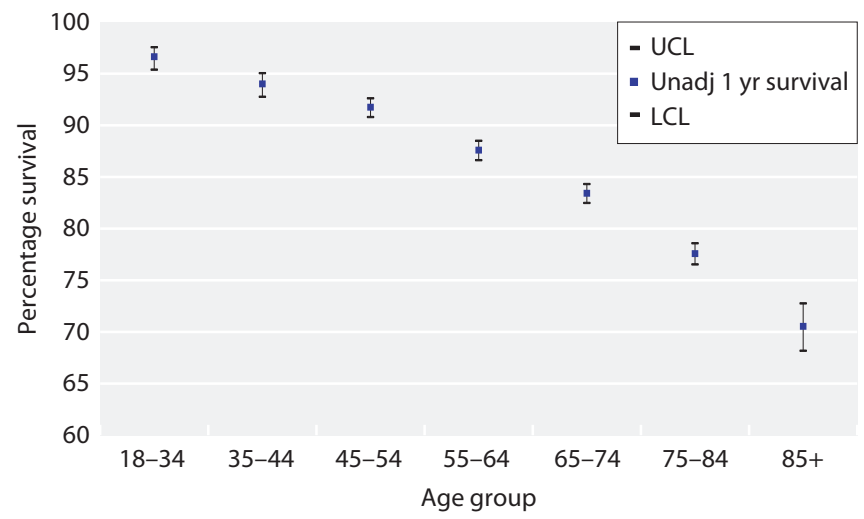

Fig. 5.23. One year survival of prevalent dialysis patients by age group, 2014 cohort

Survival in UK RRT patients in 2015

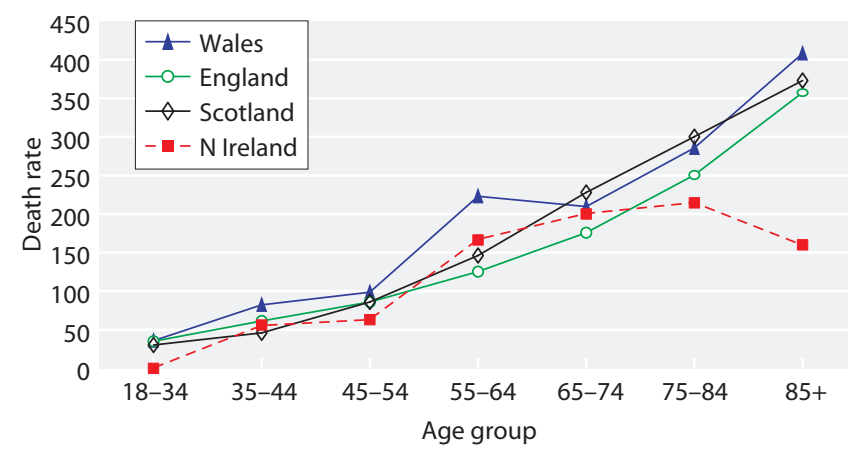

Fig. 5.24. One year death rate per 1,000 patient years by UK country and age group for prevalent dialysis patients, 2014 cohort 


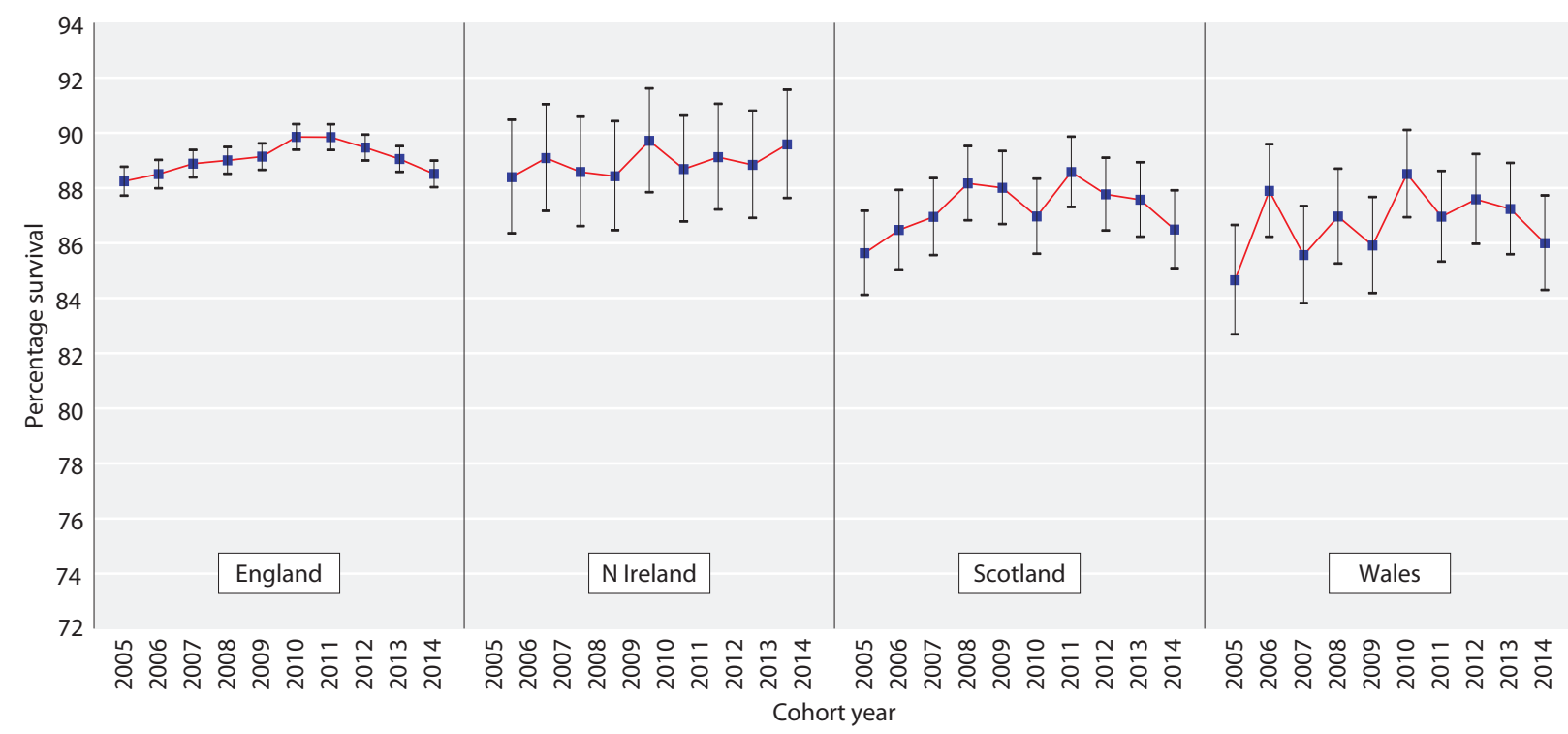

Fig. 5.25. Serial one year survival for prevalent dialysis patients by UK country, 2005 to 2014 cohort years, adjusted to age 60

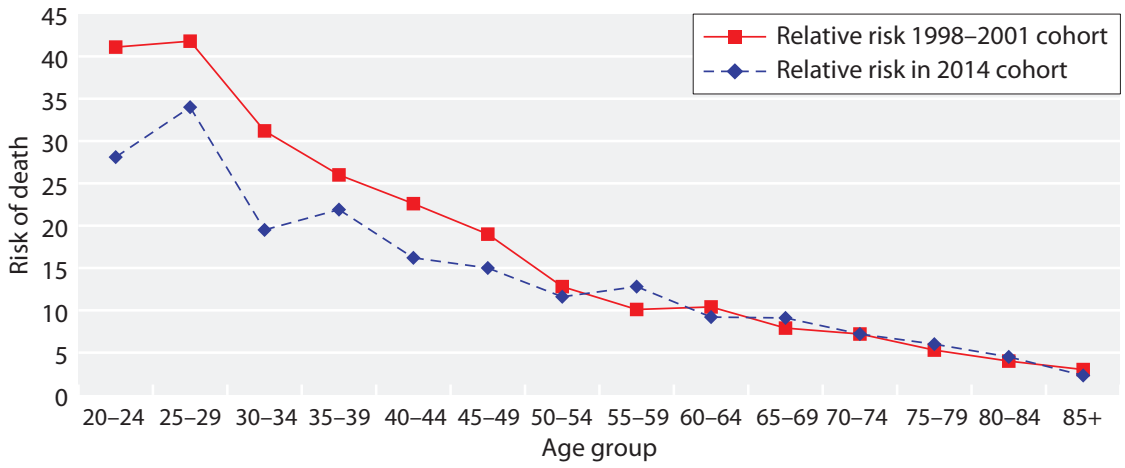

Fig. 5.26. Relative risk of death in prevalent RRT patients in the 2014 cohort compared to the 1998-2001 cohort

Table 5.14. One year survival of prevalent dialysis patients in the UK by age group and diagnosis of diabetes, 2014 cohort

\begin{tabular}{|c|c|c|c|c|}
\hline Patient group & $\begin{array}{c}\text { Patients } \\
N\end{array}$ & $\begin{array}{c}\text { Deaths } \\
N\end{array}$ & $\begin{array}{c}\text { Survival } \\
\%\end{array}$ & $95 \% C I$ \\
\hline \multicolumn{5}{|c|}{ Dialysis patients 2014 cohort } \\
\hline All age $<65$ & 12,000 & 1,021 & 90.8 & $90.3-91.3$ \\
\hline Non-diabetic $<65$ & 9,245 & 618 & 92.7 & $92.1-93.3$ \\
\hline Diabetic $<65$ & 2,755 & 403 & 84.6 & $83.2-85.9$ \\
\hline All age $65+$ & 14,437 & 2,934 & 79.4 & $78.8-80.1$ \\
\hline Non-diabetic 65+ & 11,207 & 2,251 & 79.7 & $78.9-80.4$ \\
\hline Diabetic $65+$ & 3,230 & 683 & 78.7 & $77.2-80.0$ \\
\hline
\end{tabular}

to the 1998-2001 cohort. The overall relative risk of death was 6.1 in the 2014 cohort and was similar to the relative risk in recent years.

\section{Causes of death}

\section{Data completeness}

Overall completeness of data for cause of death in the UK decreased slightly from $65.3 \%$ in 2014 to $63.5 \%$ in 2015 , with falls in the returns from all four nations.

Table 5.15. Serial one year survival of prevalent dialysis patients with a primary diagnosis of diabetes, 2005-2014 cohort years

\begin{tabular}{lccccccccccc}
\hline & \multicolumn{10}{c}{ Year } \\
\cline { 2 - 12 } Survival & 2005 & 2006 & 2007 & 2008 & 2009 & 2010 & 2011 & 2012 & 2013 & 2014 \\
\hline 1 year survival & 82.6 & 84.9 & 83.5 & 83.9 & 83.3 & 84.9 & 85.1 & 84.7 & 83.5 & 83.0 \\
Number of patients & 3,529 & 3,962 & 4,368 & 4,713 & 5,054 & 5,222 & 5,444 & 5,642 & 5,935 & 5,985 \\
\hline
\end{tabular}


Table 5.16. Death rate by age group for prevalent RRT patients, 2014 cohort, compared with the general population and with previous analyses in the 1998-2001 cohort

\begin{tabular}{|c|c|c|c|c|c|c|c|c|}
\hline Age group & $\begin{array}{c}\text { UK } \\
\text { population } \\
\text { mid 2014 } \\
\text { (thousands) }\end{array}$ & $\begin{array}{l}\text { UK deaths } \\
\text { in } 2014\end{array}$ & $\begin{array}{l}\text { Death rate } \\
\text { per } 1,000 \\
\text { population }\end{array}$ & $\begin{array}{c}\text { Expected } \\
\text { number of } \\
\text { deaths in UKRR } \\
\text { population }\end{array}$ & $\begin{array}{l}\text { UKRR } \\
\text { deaths } \\
\text { in } 2014\end{array}$ & $\begin{array}{l}\text { UKRR death } \\
\text { rate per } 1,000 \\
\text { prevalent RRT } \\
\text { patients }\end{array}$ & $\begin{array}{c}\text { Relative risk } \\
\text { of death in } \\
2014\end{array}$ & $\begin{array}{c}\text { Relative risk } \\
\text { of death } \\
\text { 1998-2001 } \\
\text { cohort }\end{array}$ \\
\hline $20-24$ & 4,295 & 1,553 & 0.4 & 0 & 10 & 10 & 28.1 & 41.1 \\
\hline $25-29$ & 4,441 & 2,041 & 0.5 & 1 & 24 & 16 & 34.0 & 41.8 \\
\hline $30-34$ & 4,382 & 2,829 & 0.6 & 2 & 29 & 13 & 19.5 & 31.2 \\
\hline $35-39$ & 4,079 & 3,913 & 1.0 & 3 & 59 & 21 & 21.9 & 26.0 \\
\hline $40-44$ & 4,299 & 6,131 & 1.4 & 6 & 95 & 23 & 16.2 & 22.6 \\
\hline $45-49$ & 4,631 & 9,868 & 2.1 & 12 & 180 & 32 & 15.0 & 19.0 \\
\hline $50-54$ & 4,565 & 14,514 & 3.2 & 21 & 242 & 37 & 11.6 & 12.8 \\
\hline $55-59$ & 3,951 & 19,483 & 4.9 & 31 & 401 & 63 & 12.8 & 10.1 \\
\hline $60-64$ & 3,502 & 27,901 & 8.0 & 48 & 438 & 73 & 9.2 & 10.4 \\
\hline $65-69$ & 3,615 & 43,902 & 12.1 & 75 & 685 & 111 & 9.1 & 7.9 \\
\hline $70-74$ & 2,725 & 54,971 & 20.2 & 103 & 742 & 146 & 7.2 & 7.2 \\
\hline $75-79$ & 2,162 & 74,463 & 34.4 & 147 & 885 & 208 & 6.0 & 5.3 \\
\hline $80-84$ & 1,584 & 99,140 & 62.6 & 170 & 755 & 279 & 4.5 & 4.0 \\
\hline $85+$ & 1,526 & 236,970 & 155.3 & 199 & 458 & 358 & 2.3 & 3.0 \\
\hline Total & 49,757 & 597,679 & 12.0 & 816 & 5,003 & 90 & 6.1 & 7.7 \\
\hline
\end{tabular}

The largest fall in data completeness was an $8.3 \%$ fall in Scotland (appendix 1, table 5.27). There was substantial variability in the completeness of cause of death between centres, with some returning no data whilst others achieved 100\% completeness. Several centres have shown substantial improvement in data returns (appendix 1, table 5.27).

\section{Causes of death in incident RRT patients}

The number and proportion of patients in the cohort with missing data for cause of death is shown in the last row of each table for cause of death (tables 5.17 to 5.21).
Causes of death within the first 90 days

In the first 90 days after start of RRT, cardiac disease was the most common cause of death in both age groups. However, infection and treatment withdrawal as a cause of death were more common in older patients (aged $65+$ ), whereas malignancy was more common in younger patients ( $<65$ years old) (table 5.17).

\section{Causes of death within one year after 90 days}

In the year after the first 90 days, treatment withdrawal as a cause of death was more common in older patients (aged 65+), whereas cardiac disease was more common in younger patients ( $<65$ years old) (table 5.18).

Table 5.17. Causes of death in the first 90 days for incident RRT patients by age group, 2000-2014 cohort

\begin{tabular}{|c|c|c|c|c|c|c|}
\hline \multirow[b]{2}{*}{ Cause of death } & \multicolumn{2}{|c|}{ All age groups } & \multicolumn{2}{|c|}{$<65$ years } & \multicolumn{2}{|c|}{$\geqslant 65$ years } \\
\hline & $N$ & $\%$ & $N$ & $\%$ & $N$ & $\%$ \\
\hline Cardiac disease & 830 & 26 & 192 & 28 & 638 & 26 \\
\hline Cerebrovascular disease & 141 & 4 & 32 & 5 & 109 & 4 \\
\hline Infection & 563 & 18 & 100 & 14 & 463 & 19 \\
\hline Malignancy & 294 & 9 & 90 & 13 & 204 & 8 \\
\hline Treatment withdrawal & 510 & 16 & 71 & 10 & 439 & 18 \\
\hline Other & 713 & 22 & 179 & 26 & 534 & 21 \\
\hline Uncertain & 134 & 4 & 27 & 4 & 107 & 4 \\
\hline Total & 3,185 & & 691 & & 2,494 & \\
\hline Missing data & 2,838 & 47 & 623 & 47 & 2,215 & 47 \\
\hline
\end{tabular}


Table 5.18. Cause of death one year after 90 days for incident RRT patients by age group, 2000-2014 cohort

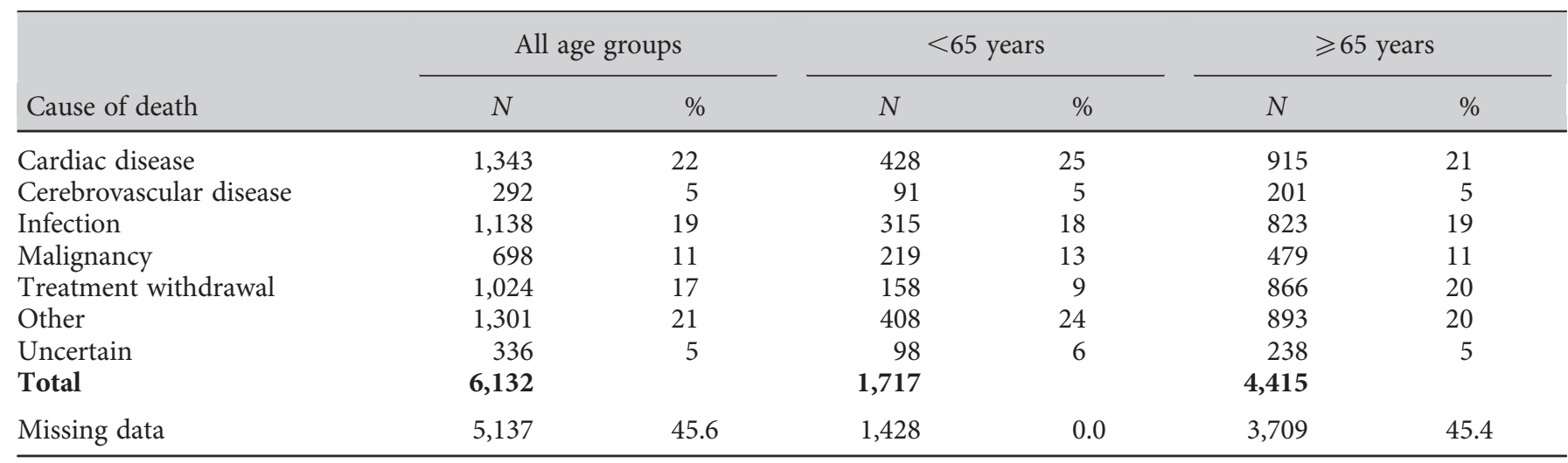

Table 5.19. Cause of death in prevalent RRT patients by modality, 2014 cohort

\begin{tabular}{|c|c|c|c|c|c|c|}
\hline \multirow[b]{2}{*}{ Causes of death } & \multicolumn{2}{|c|}{ All modalities } & \multicolumn{2}{|c|}{ Dialysis } & \multicolumn{2}{|c|}{ Transplant } \\
\hline & $N$ & $\%$ & $N$ & $\%$ & $N$ & $\%$ \\
\hline Cerebrovascular disease & 138 & 4 & 114 & 4 & 24 & 4 \\
\hline Infection & 688 & 21 & 554 & 21 & 134 & 24 \\
\hline Malignancy & 327 & 10 & 201 & 7 & 126 & 22 \\
\hline Uncertain & 144 & 4 & 115 & 4 & 29 & 5 \\
\hline Total & 3,258 & & 2,697 & & 561 & \\
\hline Missing data & 1,747 & 35 & 1,439 & 35 & 308 & 35 \\
\hline
\end{tabular}

Although cardiac disease remained the leading cause of death in in both older and younger age groups at one year after the first 90 days, it has decreased over time. There has been a gradual increase in treatment withdrawal over recent years as cause of death at 90 days in older patients (aged 65+).
Cause of death in prevalent RRT patients in the 2014 cohort

Table 5.19 shows the comparison of cause of death for prevalent dialysis and transplant patients in the 2014 cohort. Cardiac disease as a cause of death was less common in patients with a transplant who were a highly

Table 5.20. Cause of death in prevalent dialysis patients by age group, 2014 cohort

\begin{tabular}{|c|c|c|c|c|c|c|}
\hline \multirow[b]{2}{*}{ Cause of death } & \multicolumn{2}{|c|}{ All age groups } & \multicolumn{2}{|c|}{$<65$ years } & \multicolumn{2}{|c|}{$\geqslant 65$ years } \\
\hline & $N$ & $\%$ & $N$ & $\%$ & $N$ & $\%$ \\
\hline Cardiac disease & 613 & 23 & 196 & 27 & 417 & 21 \\
\hline Cerebrovascular disease & 114 & 4 & 38 & 5 & 76 & 4 \\
\hline Infection & 554 & 21 & 156 & 22 & 398 & 20 \\
\hline Malignancy & 201 & 7 & 50 & 7 & 151 & 8 \\
\hline Treatment withdrawal & 566 & 21 & 98 & 14 & 468 & 24 \\
\hline Other & 534 & 20 & 155 & 21 & 379 & 19 \\
\hline Uncertain & 115 & 4 & 32 & 4 & 83 & 4 \\
\hline Total & 2,697 & & 725 & & 1,972 & \\
\hline No cause of death data & 1,439 & 35 & 356 & 33 & 1,083 & 35 \\
\hline
\end{tabular}


Table 5.21. Cause of death in prevalent transplant patients by age group, 2014 cohort

\begin{tabular}{|c|c|c|c|c|c|c|}
\hline \multirow[b]{2}{*}{ Cause of death } & \multicolumn{2}{|c|}{ All age groups } & \multicolumn{2}{|c|}{$<65$ years } & \multicolumn{2}{|c|}{$\geqslant 65$ years } \\
\hline & $N$ & $\%$ & $N$ & $\%$ & $N$ & $\%$ \\
\hline Cardiac disease & 101 & 18 & 54 & 21 & 47 & 15 \\
\hline Cerebrovascular disease & 24 & 4 & 13 & 5 & 11 & 4 \\
\hline Infection & 134 & 24 & 58 & 23 & 76 & 25 \\
\hline Malignancy & 126 & 22 & 58 & 23 & 68 & 22 \\
\hline Treatment withdrawal & 15 & 3 & 3 & 1 & 12 & 4 \\
\hline Other & 132 & 24 & 61 & 24 & 71 & 23 \\
\hline Uncertain & 29 & 5 & 10 & 4 & 19 & 6 \\
\hline Total & 561 & & 257 & & 304 & \\
\hline No cause of death data & 308 & 35 & 142 & 36 & 166 & 35 \\
\hline
\end{tabular}

selected group of patients. Malignancy was responsible for a far greater percentage of deaths in prevalent patients with a transplant than in those receiving dialysis, and to a lesser extent infection too. Treatment withdrawal was a more common cause of death in the prevalent dialysis population.

Table 5.20 shows the cause of death for prevalent dialysis patients in the 2014 cohort, divided into subgroups according to age. Again, cardiac disease was the leading cause of death overall. Cardiac disease represented a higher proportion of all deaths (amongst those where cause of death was known) in younger $(<65$ years) dialysis patients, although the absolute number of cardiac deaths were higher amongst those aged $\geqslant 65$ years $(27 \%$ versus $21 \%)$. Prevalent dialysis patients aged $\geqslant 65$ years were substantially more likely to withdraw from treatment than younger patients (24\% and $14 \%$ respectively).

Table 5.21 shows the cause of death for prevalent transplant patients in the 2014 cohort, divided into subgroups according to age. It shows that cardiac disease was more common in the younger age group (similar to that seen for dialysis patients). The proportions of other causes of death were relatively similar between older and younger patients.

Figure 5.27 shows cause of death for prevalent RRT patients over time between 2000 to 2014. Cardiovascular mortality decreased from year 2000 to 2005 and has remained static since, whilst treatment withdrawal as a cause of death has increased since 2009 onwards. Infection and malignancy as cause of death have remained static over the period (figure 5.27).

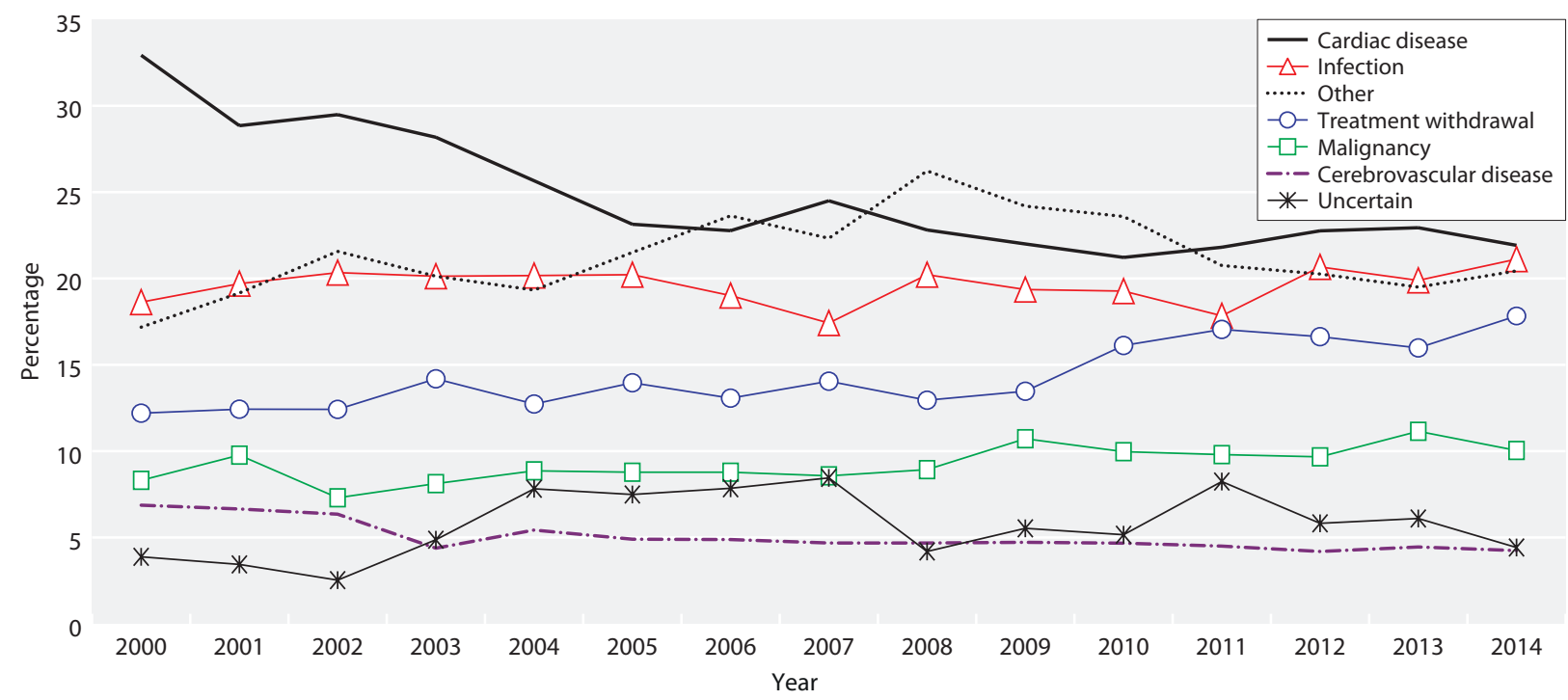

Fig. 5.27. Cause of death in prevalent RRT patients by cohort year (2000-2014) 


\section{Discussion}

Survival of incident patients on RRT at 90 days (adjusted to age 60) was unchanged overall compared to the preceding year. When analysed according to age group, 90 day survival improved for those $\geqslant 65$ years whilst it fell for the younger patients. Incident one year after 90 days survival (adjusted to age 60) fell slightly in the 2014 cohort compared to 2013, and this was reflected in both age groups. There was no difference in survival by gender. Long term survival of incident patients on RRT continued to improve gradually over time.

There were differences in short term incident survival (90 days and one year after 90 days) by combined age group and diagnosis of diabetes: 90 day survival was better for those with diabetes across all age groups. For survival one year after 90 days, in the youngest group survival was much better for those without diabetes, however, this association was not seen in the older age groups, where survival was more similar between those with and without diabetes. Long-term survival showed a similar picture, where younger $(<65$ years) patients without diabetes survived much better than similar aged patients with diabetes. Survival was similar for older patients ( $\geqslant 65$ years) with and without diabetes.

One year age adjusted survival for prevalent dialysis patients was static in 2014 compared to 2013 (88.3\% and $88.6 \%$ respectively). Prevalent dialysis patient survival in the UK seems to have peaked in 2011 and has been slightly lower in more recent years. The age adjusted one year survival for prevalent dialysis patients with diabetic primary renal disease in the UK has decreased slightly from 2012 onwards. The relative one year risk of death on RRT at age 20-24 years is 28 times that of the same age group in the general population, but has improved markedly over time (compared with a relative risk of 41 in the 1998-2001 cohort of the same age). For older patients (70-74 years) the relative risk is lower at 7.2 compared with the general population of a similar age, but this relative risk has not improved over time.

In the prevalent dialysis population for whom data regarding cause of death were available, cardiovascular disease was the most common cause of death accounting for $23 \%$ of deaths. Infection accounted for $21 \%$ of deaths and treatment withdrawal for $21 \%$ of deaths, with differences seen according to age group. In contrast, infection was the most common cause of death in prevalent transplant patients $(24 \%)$, whilst malignancy accounted for $22 \%$ and cardiac disease $18 \%$ of all deaths. Trends in causes of death over time (2000-2014) show a decrease in cardiovascular disease, an increase in treatment withdrawal and a plateauing of deaths related to infection.

Variability in survival between centres was still evident, with some centres appearing as outliers in the data (below the lower 95\% and above the upper 95\% confidence limits) in incident RRT and prevalent dialysis patient survival. The survival analyses in this chapter have not been adjusted for any case-mix factors except for age. Differences in proportions of primary renal diagnosis, ethnicity and comorbidity have not been considered due to missing data from some renal centres. Although research has suggested that adjustment for comorbidity only explains a modest part of the variance in ERF patient outcomes [11], at centre level, the prevalence of comorbidities could vary substantially between renal centres and it would be expected that adjustment for comorbidity may explain a proportion of the variance in survival. The UK Renal Registry regularly evaluates the effect of adjusting for primary renal diagnosis and comorbidity in addition to age in those centres returning $\geqslant 85 \%$ of comorbidities and repeatedly shows that, at centre level, there is clear benefit for some centres in adjusting for primary renal diagnosis and comorbidities. Research using comorbid conditions identified from hospital episode statistics (HES) data for RRT patients in England during 2002-2006 showed that adjustment for HES-derived case-mix, including comorbid conditions, affected the position on the funnel plot and outlying status of some renal centres for incident patients and reduced outlying centres from four to one [10].

Routine linkage of the UK Renal Registry data with hospital admissions information in the UK will allow the UKRR to report on survival adjusted for case-mix (age, ethnicity, primary renal diagnosis and comorbidity) in future UKRR reports. This will provide an improved comparison between centres and more accurate identification and location of outlying centres on funnel plots.

There is also considerable centre level variability in the early hazard of death (e.g. first six months) from start of RRT. The proportion of deaths in the first 90 days of starting RRT varied at centre level and, in some centres, the proportion was very low or even zero. This may be due to unreported deaths in patients that die within the first 90 days of starting RRT for ERF. Alternatively, it may be due to those patients being described as having acute kidney injury (AKI) and therefore not included in the historical UKRR data collection. From January 2015, the UKRR began collecting data for patients 
receiving RRT for acute dialysis in renal centres in England and some Welsh centres, therefore future survival analyses will be able to take account of these discrepancies. In addition, from January 2016 the UKRR began collecting data for patients with chronic kidney disease (CKD) Stage 4 and 5 seen in renal centres in England, Wales and Northern Ireland, which will improve the

\section{References}

1 Plantinga LC, Fink NE, Levin NW, et al. Early, Intermediate, and LongTerm Risk Factors for Mortality in Incident Dialysis Patients: The Choices for Healthy Outcomes in Caring for ESRD (CHOICE) Study. American journal of kidney diseases: the official journal of the National Kidney Foundation 2007;49(6):831-40

2 Miskulin DC, Meyer KB, Martin AA, et al. Comorbidity and its change predict survival in incident dialysis patients. American journal of kidney diseases: the official journal of the National Kidney Foundation 2003; 41(1):149-61

3 Nitsch D, Burden R, Steenkamp R, Ansell D, Byrne C, Caskey F, et al. Patients with diabetic nephropathy on renal replacement therapy in England and Wales. QJM-an International Journal of Medicine. 2007 Sep;100(9):551-60

4 Roderick P, Byrne C, Casula A, Steenkamp R, Ansell D, Burden R, et al. Survival of patients from South Asian and Black populations starting renal replacement therapy in England and Wales. Nephrology Dialysis Transplantation. 2009;24(12):3774-82

5 Tomson C, Maggs C. UK Renal Registry 12th Annual Report (December 2009): Chapter 2: introduction. Nephron Clin Pract. 2010;115(suppl 1): c3-8

6 Ford DJ, Fogarty DG, Steenkamp R, Tomson CRV, Ben-Shlomo Y, Ansell D. Chapter 13: The UK Renal Registry Advanced CKD Study: identification of patients who opt for conservative care rather than RRT for their advanced kidney disease. These innovations in data collection will result in an improvement in the accuracy of survival estimates for patients with advanced kidney disease in the UK.

Conflicts of interest: the authors declare no conflicts of interest frequency of incorrect reporting of date of start of RRT. Nephron Clinical Practice;115(suppl 1):c271-c78

7 Malek SK, Keys BJ, Kumar S, Milford E, Tullius SG. Racial and ethnic disparities in kidney transplantation. Transplant International 2011;24(5):419-24 doi: 10.1111/j.1432-2277.2010.01205.x [published Online First: Epub Date]

8 Office for National Statistics. www.ons.gov.uk, http://www.ons.gov.uk/ ons/dcp171778 238743.pdf

9 Ansell D, Roderick P, Hodsman A, Ford D, Steenkamp R, Tomson C. UK Renal Registry 11th Annual Report (December 2008): Chapter 7 Survival and cause of death of UK adult patients on renal replacement therapy in 2007: national and centre-specific analyses. Nephron Clin Pract. 2009;111(suppl 1):c113-39

10 Fotheringham, J., et al., Variation in centre-specific survival in patients starting renal replacement therapy in England is explained by enhanced comorbidity information from hospitalization data. Nephrology Dialysis Transplantation. 29(2): p. 422-430

11 van Manen JG, van Dijk PCW, Stel VS, Dekker FW, Cleries M, Conte F, et al. Confounding effect of comorbidity in survival studies in patients on renal replacement therapy. Nephrology Dialysis Transplantation. 2007; 22(1):187-95 


\section{Appendix 1: Survival tables}

Table 5.22. One year after 90 day incident RRT survival percentage by centre, 2014 cohort, unadjusted and adjusted to age 60

\begin{tabular}{|c|c|c|c|c|c|c|c|}
\hline Centre & $\begin{array}{c}\text { Unadjusted } \\
\text { one year after } \\
90 \text { days } \\
\text { survival }\end{array}$ & $\begin{array}{l}\text { Adjusted one } \\
\text { year after } \\
90 \text { days } \\
\text { survival }\end{array}$ & $\begin{array}{c}\text { Adjusted one } \\
\text { year after } \\
90 \text { days } \\
95 \% \text { CI }\end{array}$ & Centre & $\begin{array}{l}\text { Unadjusted } \\
\text { one year after } \\
90 \text { days } \\
\text { survival }\end{array}$ & $\begin{array}{l}\text { Adjusted one } \\
\text { year after } \\
90 \text { days } \\
\text { survival }\end{array}$ & $\begin{array}{c}\text { Adjusted one } \\
\text { year after } \\
90 \text { days } \\
95 \% \text { CI }\end{array}$ \\
\hline England & & & & Redng & 92.2 & 95.0 & $91.4-98.7$ \\
\hline B Heart & 90.9 & 93.6 & $89.8-97.5$ & Salford & 87.9 & 90.5 & $86.1-95.0$ \\
\hline B QEH & 87.7 & 90.3 & $86.9-93.9$ & Sheff & 86.3 & 90.6 & $86.6-94.7$ \\
\hline Basldn & 84.5 & 88.6 & $79.9-98.3$ & Shrew & 77.0 & 83.5 & $75.9-91.8$ \\
\hline Bradfd & 81.3 & 82.5 & $74.0-91.9$ & Stevng & 87.3 & 90.9 & $86.9-95.2$ \\
\hline Brightn & 86.7 & 90.6 & $86.4-95.0$ & Sthend & 85.6 & 89.2 & $80.0-99.5$ \\
\hline Bristol & 91.7 & 94.2 & $90.9-97.6$ & Stoke & 87.2 & 91.8 & $87.6-96.2$ \\
\hline Camb & 87.9 & 91.5 & 87.4-95.7 & Sund & 84.6 & 87.9 & $81.2-95.2$ \\
\hline Carlis & 84.5 & 88.3 & $80.0-97.4$ & Truro & 78.9 & 85.4 & $76.0-95.9$ \\
\hline Carsh & 87.1 & 91.0 & $88.0-94.1$ & Wirral & 82.9 & 86.5 & $78.3-95.6$ \\
\hline Chelms & 85.1 & 88.1 & $80.8-96.1$ & Wolve & 82.7 & 88.3 & $82.5-94.5$ \\
\hline Colchr & 82.4 & 87.7 & $79.2-97.2$ & York & 83.0 & 87.6 & $79.5-96.5$ \\
\hline Covnt & 88.7 & 92.4 & $88.6-96.5$ & & & & \\
\hline Derby & 94.9 & 95.7 & $91.1-100.0$ & N Ireland & & & \\
\hline Donc & 88.5 & 91.6 & $85.5-98.2$ & Antrim & 69.8 & 81.8 & $71.8-93.2$ \\
\hline Dorset & 85.2 & 90.6 & $85.7-95.8$ & Belfast & 85.8 & 88.5 & $81.3-96.2$ \\
\hline Dudley & 88.5 & 91.4 & $85.2-98.2$ & Ulster & 90.9 & 92.8 & $83.8-100.0$ \\
\hline Exeter & 87.2 & 92.4 & $88.9-96.1$ & West NI & 83.8 & 88.7 & $79.0-99.6$ \\
\hline Glouc & 88.2 & 92.7 & $87.9-97.7$ & & & & \\
\hline Hull & 89.3 & 92.2 & $87.5-97.2$ & Scotland & & & \\
\hline Ipswi & 97.1 & 98.6 & $96.0-100.0$ & Abrdn & 92.6 & 94.1 & $88.6-99.8$ \\
\hline Kent & 87.4 & 91.4 & $87.6-95.3$ & Airdrie & 85.7 & 88.1 & $80.7-96.1$ \\
\hline L Barts & 85.9 & 87.1 & $83.4-91.0$ & D \& Gall & 95.0 & 97.1 & $91.9-100.0$ \\
\hline L Guys & 91.9 & 93.0 & $89.3-96.9$ & Dundee & 87.2 & 90.6 & $83.8-98.0$ \\
\hline L Kings & 92.1 & 93.8 & $90.4-97.2$ & Edinb & 89.1 & 88.5 & $81.8-95.8$ \\
\hline L Rfree & 88.9 & 92.0 & $88.9-95.1$ & Glasgw & 82.9 & 86.3 & $81.9-91.0$ \\
\hline L St.G & 89.7 & 91.7 & $86.7-97.0$ & Klmarnk & 86.1 & 87.6 & $78.2-98.1$ \\
\hline L West & 87.7 & 90.5 & 87.7-93.4 & & & & \\
\hline Leeds & 88.6 & 89.6 & $85.1-94.4$ & Wales & & & \\
\hline Leic & 88.9 & 91.4 & $88.3-94.6$ & Bangor & 90.0 & 93.6 & $85.6-100.0$ \\
\hline Liv Ain & 85.7 & 89.2 & $82.1-97.0$ & Clwyd & 86.7 & 89.7 & $80.9-99.6$ \\
\hline Liv Roy & 85.6 & 87.4 & $81.8-93.3$ & Cardff & 82.5 & 87.1 & $82.7-91.8$ \\
\hline M RI & 82.7 & 85.4 & $80.4-90.7$ & Swanse & 83.7 & 89.8 & $85.3-94.6$ \\
\hline Middlbr & 89.1 & 92.8 & $88.7-97.2$ & Wrexm & 89.7 & 94.5 & $88.7-100.0$ \\
\hline Newc & 88.7 & 91.3 & $86.5-96.3$ & & & & \\
\hline Norwch & 80.0 & 87.4 & $81.7-93.6$ & England & 87.4 & 90.4 & $89.6-91.2$ \\
\hline Nottm & 89.6 & 92.5 & $88.2-97.1$ & N Ireland & 83.2 & 87.4 & 82.9-92.2 \\
\hline Oxford & 82.9 & 86.6 & $82.1-91.3$ & Scotland & 87.8 & 90.0 & $87.7-92.4$ \\
\hline Plymth & 84.0 & 88.8 & $81.8-96.3$ & Wales & 84.4 & 89.2 & $86.5-92.1$ \\
\hline Ports & 85.4 & 88.5 & $84.8-92.4$ & UK & 87.1 & 90.2 & $89.4-91.1$ \\
\hline Prestn & 91.0 & 92.9 & $89.3-96.7$ & & & & \\
\hline
\end{tabular}

Excluded: Inverness, Kirkcaldy, Newry due to $<20$ patients or no deaths recorded for the year 
Table 5.23. Ninety day incident RRT survival percentage by centre, 2014 cohort, unadjusted and adjusted to age 60

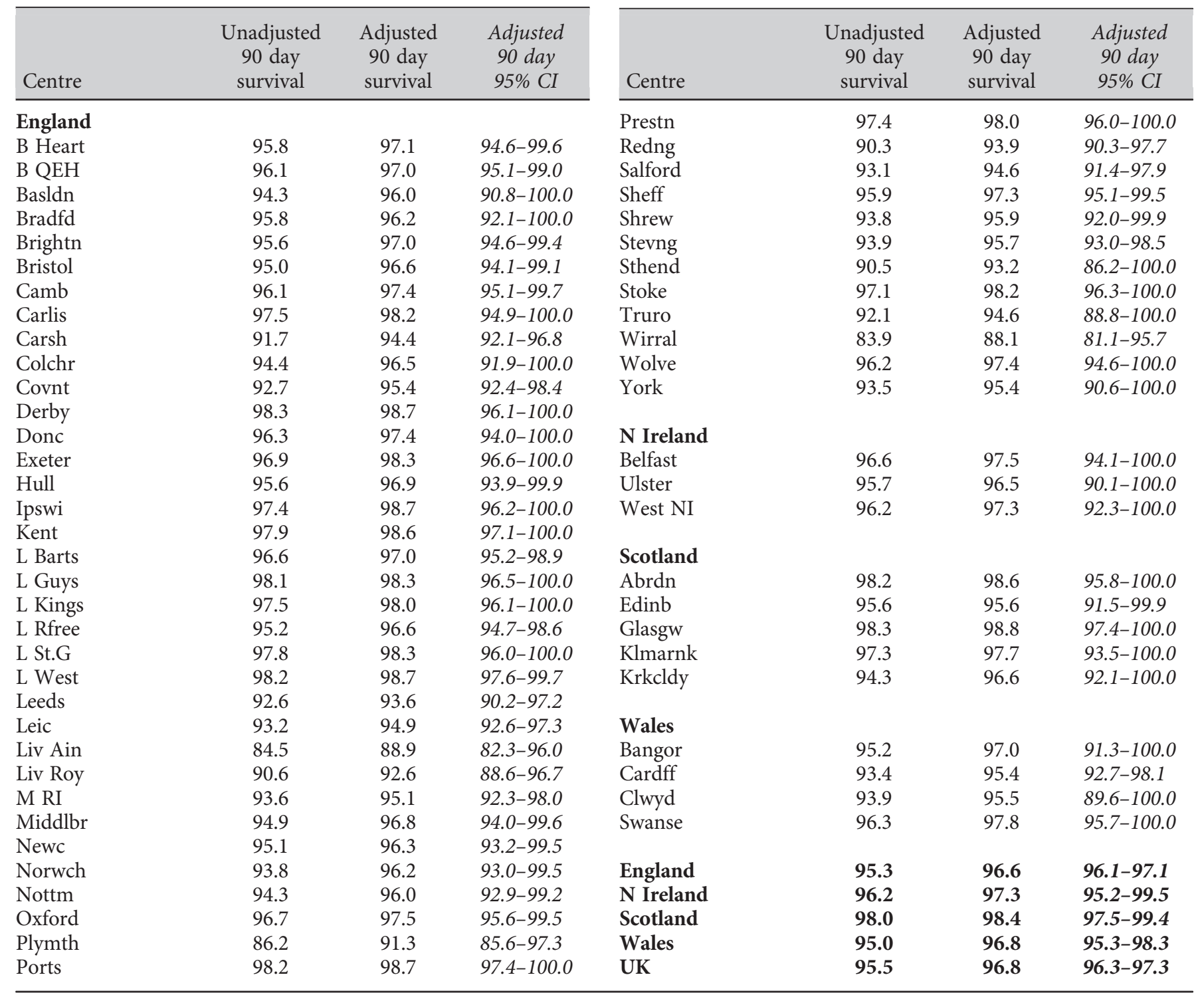

Centres excluded 2014: $<20$ patients (Newry, Inverns), no deaths recorded in the first 90 days of RRT (Dudley, Chelms, Dorset, Glouc, Sund, Antrim, D\&Gall, Dundee, Airdrie, Wrexm) 
Table 5.24. One year after 90 day incident RRT survival percentage by centre for incident RRT cohort years 2005-2014, adjusted to age 60

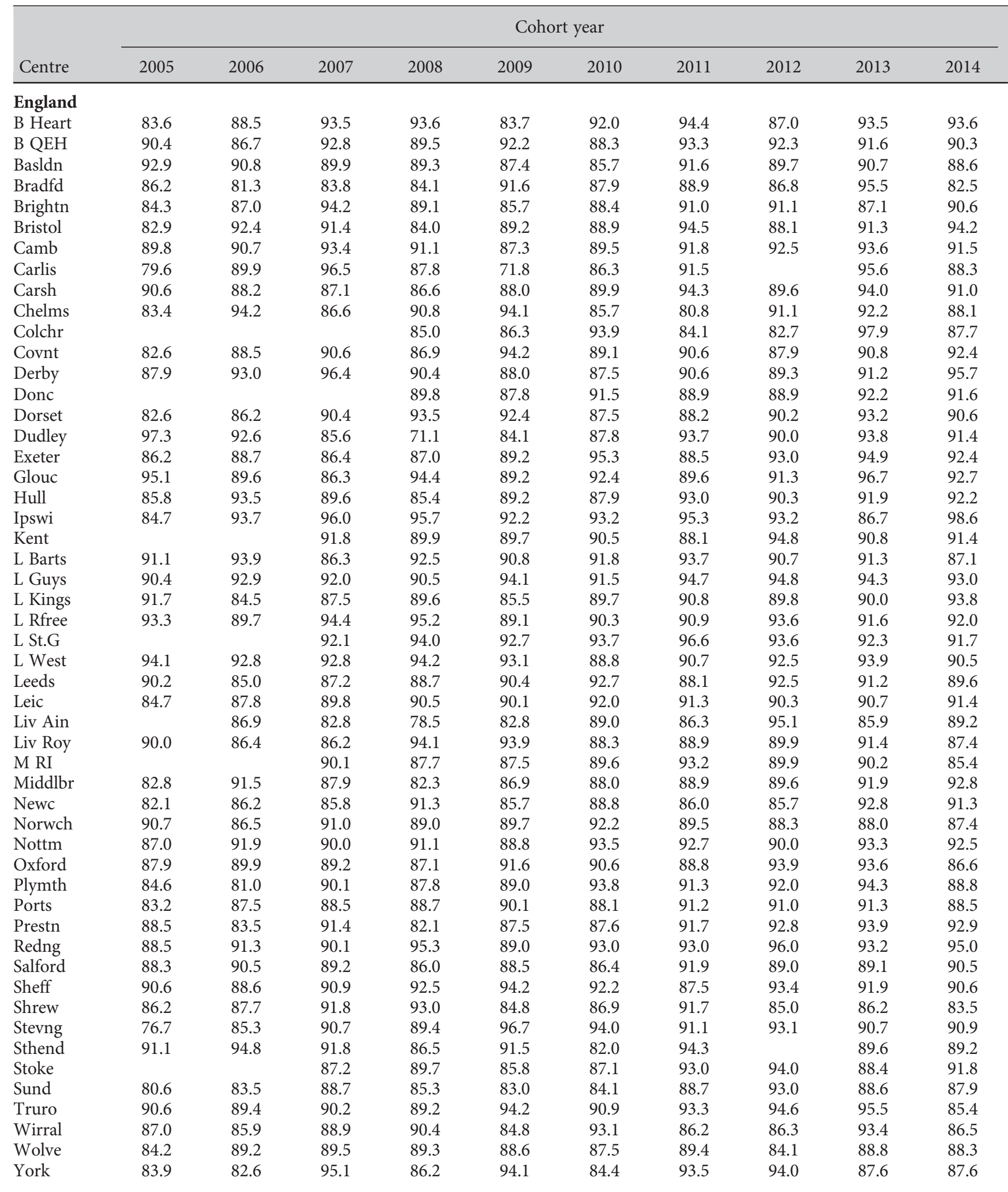


Table 5.24. Continued

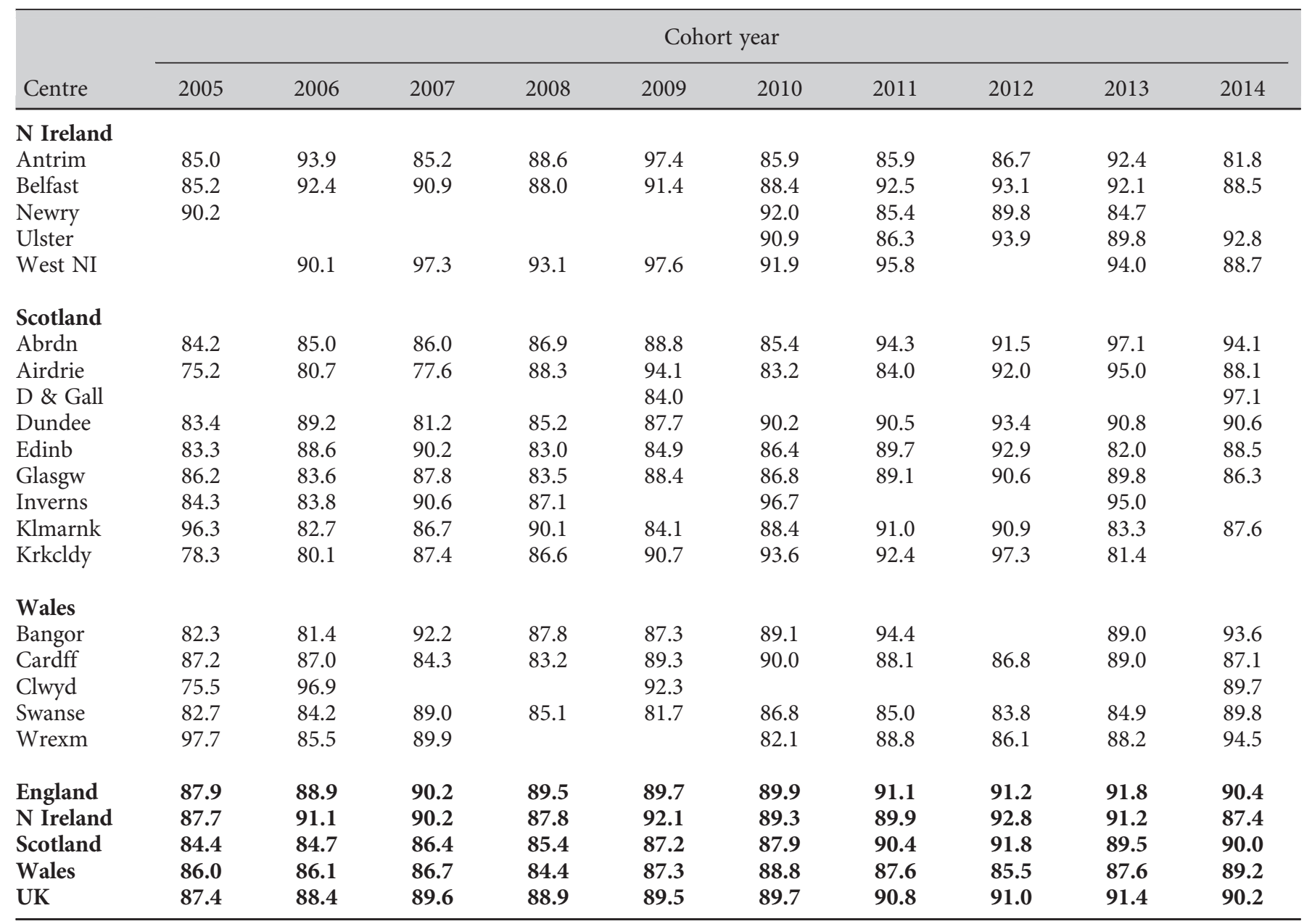

Blank cells: centres with either less than 20 patients, no deaths or no data contribution to the UKRR for that year 
Table 5.25. Incident RRT survival percentage after 90 days from start of RRT by centre for incident RRT cohort years 2010-2014, adjusted to age 60

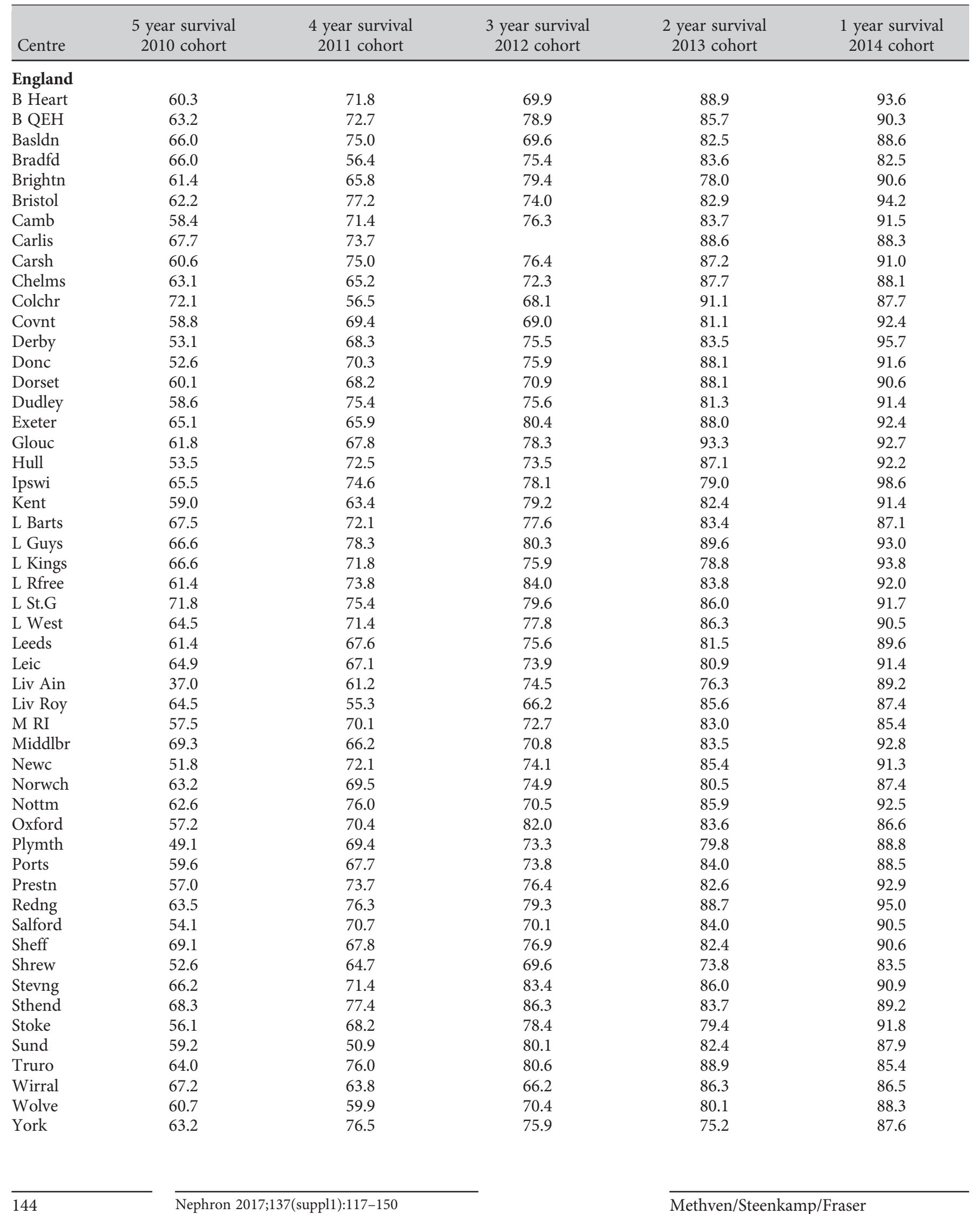


Table 5.25. Continued

\begin{tabular}{|c|c|c|c|c|c|}
\hline Centre & $\begin{array}{l}5 \text { year survival } \\
2010 \text { cohort }\end{array}$ & $\begin{array}{l}4 \text { year survival } \\
2011 \text { cohort }\end{array}$ & $\begin{array}{l}3 \text { year survival } \\
2012 \text { cohort }\end{array}$ & $\begin{array}{l}2 \text { year survival } \\
2013 \text { cohort }\end{array}$ & $\begin{array}{c}1 \text { year survival } \\
2014 \text { cohort }\end{array}$ \\
\hline \multicolumn{6}{|l|}{ N Ireland } \\
\hline Antrim & 44.8 & 76.4 & 75.9 & 89.8 & 81.8 \\
\hline Belfast & 53.1 & 67.3 & 75.6 & 87.9 & 88.5 \\
\hline Newry & 76.3 & 56.1 & 69.2 & 84.7 & \\
\hline Ulster & 68.5 & 63.2 & 75.1 & 85.1 & 92.8 \\
\hline West NI & 63.8 & 76.3 & 86.1 & 81.4 & 88.7 \\
\hline \multicolumn{6}{|l|}{ Scotland } \\
\hline Abrdn & 61.1 & 62.5 & 78.2 & 82.0 & 94.1 \\
\hline Airdrie & 52.2 & 55.4 & 67.7 & 80.8 & 88.1 \\
\hline D \& Gall & & & & & 97.1 \\
\hline Dundee & 62.0 & 71.2 & 82.3 & 86.4 & 90.6 \\
\hline Edinb & 58.1 & 68.8 & 80.3 & 74.6 & 88.5 \\
\hline Glasgw & 55.8 & 60.6 & 76.6 & 83.7 & 86.3 \\
\hline Inverns & 73.8 & & & 89.8 & \\
\hline Klmarnk & 57.6 & 50.4 & 77.8 & 74.1 & 87.6 \\
\hline Krkcldy & 55.4 & 54.1 & 59.4 & 68.2 & \\
\hline \multicolumn{6}{|l|}{ Wales } \\
\hline Bangor & 47.4 & 57.8 & & 84.0 & 93.6 \\
\hline Cardff & 62.6 & 64.7 & 72.0 & 80.3 & 87.1 \\
\hline Clwyd & 42.9 & & & & 89.7 \\
\hline Swanse & 55.7 & 65.2 & 69.0 & 76.6 & 89.8 \\
\hline Wrexm & 57.7 & 60.9 & 61.1 & 80.6 & 94.5 \\
\hline England & 61.9 & 70.0 & 76.1 & 84.0 & 90.4 \\
\hline N Ireland & 59.3 & 67.5 & 76.7 & 86.4 & 87.4 \\
\hline Scotland & 57.8 & 62.5 & 76.1 & 80.5 & 90.0 \\
\hline Wales & 57.9 & 63.6 & 69.8 & 79.1 & 89.2 \\
\hline UK & 61.3 & 69.1 & 75.8 & 83.5 & 90.2 \\
\hline
\end{tabular}

Blank cells: centres with less than 20 patients for that year or no deaths or no data contribution to the UKRR for that year 
Table 5.26. One year prevalent dialysis patient survival percentage by centre for prevalent cohort years 2005-2014, adjusted to age 60

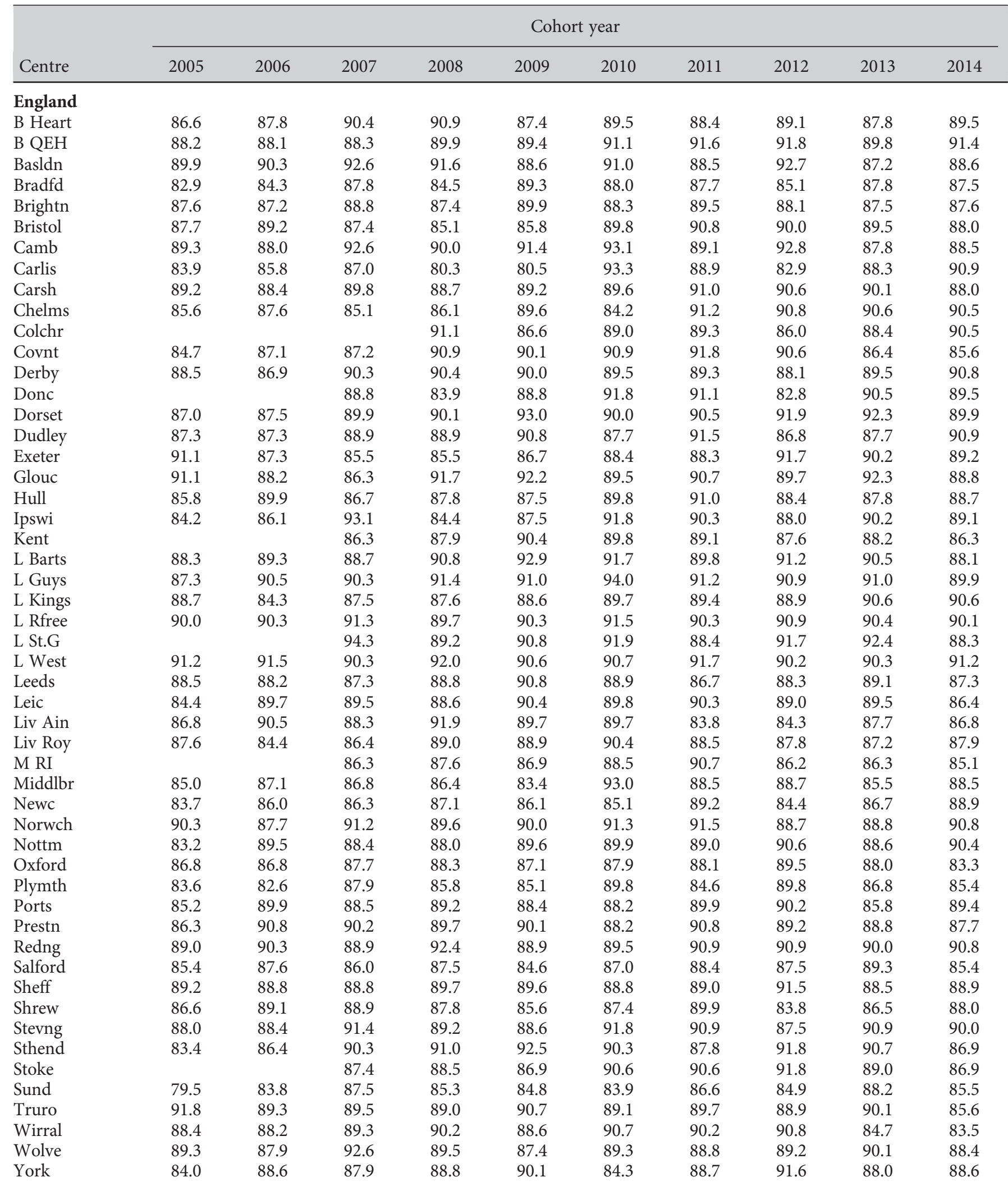


Table 5.26. Continued

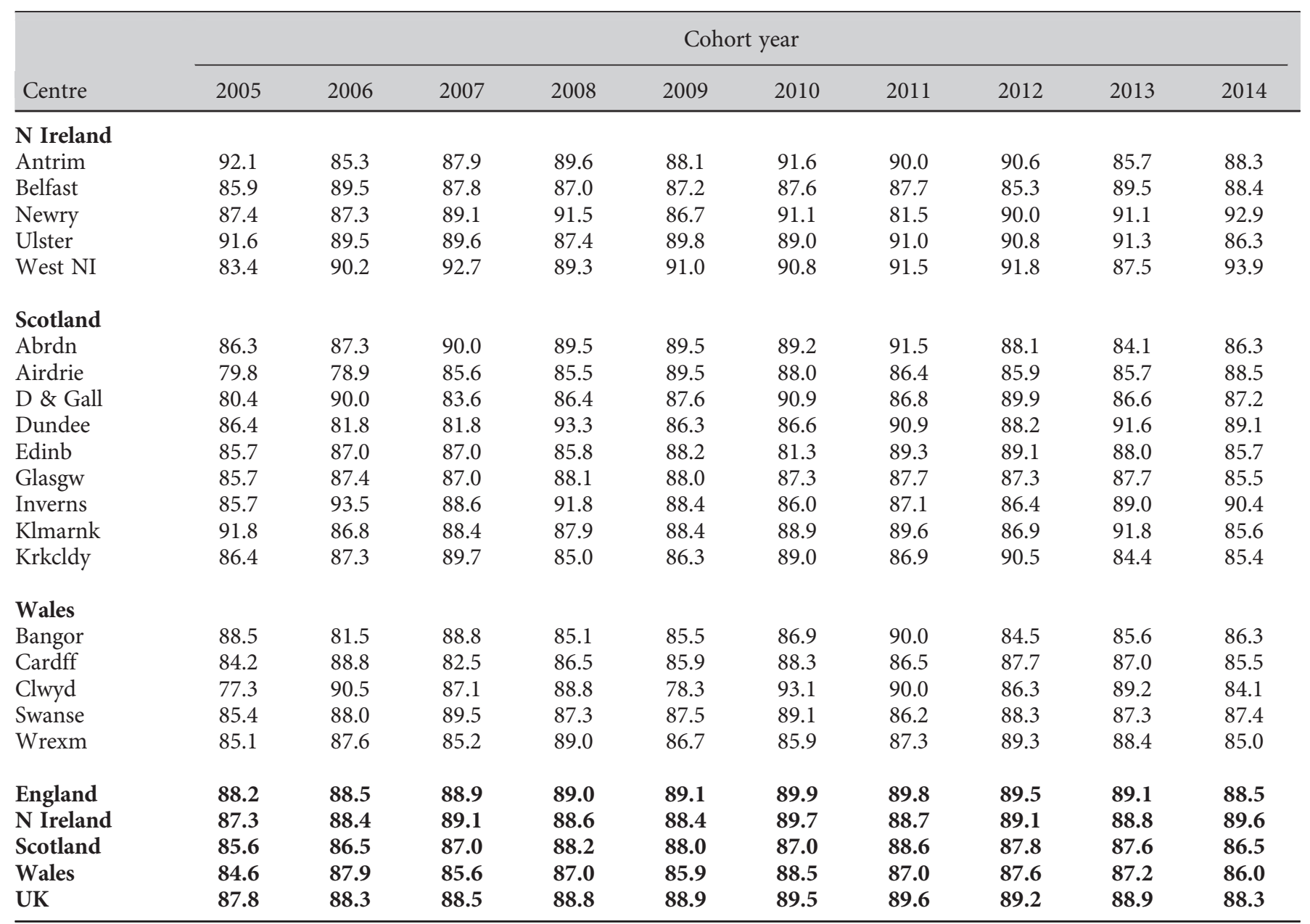

Blank cells: centres with less than 20 patients, no deaths or no data contribution to the UKRR for that year 
Table 5.27. Percentage completeness of EDTA cause of death for prevalent patients by centre and year of death, 2006 to 2015

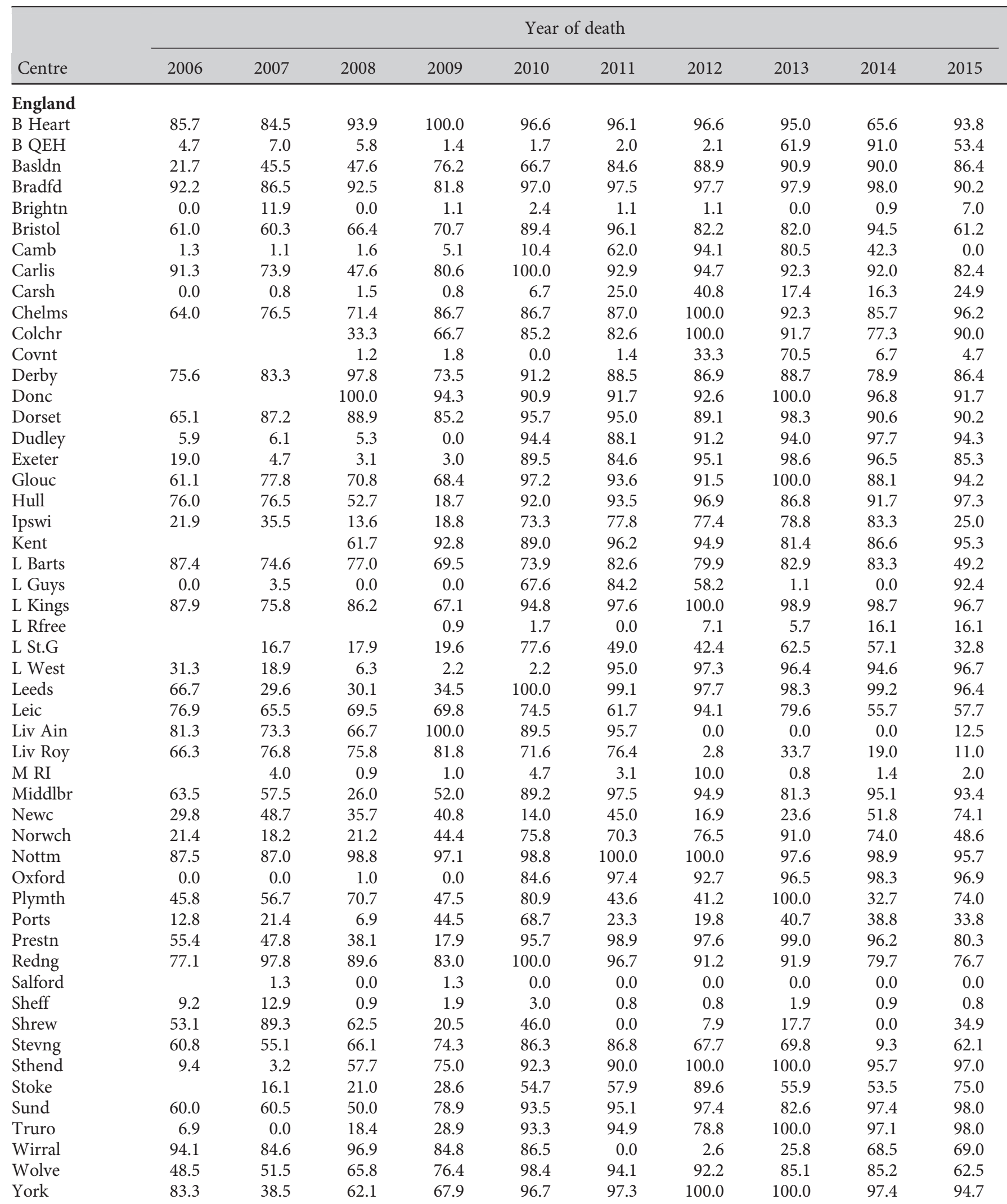


Table 5.27. Continued

\begin{tabular}{|c|c|c|c|c|c|c|c|c|c|c|}
\hline \multirow[b]{2}{*}{ Centre } & \multicolumn{10}{|c|}{ Year of death } \\
\hline & 2006 & 2007 & 2008 & 2009 & 2010 & 2011 & 2012 & 2013 & 2014 & 2015 \\
\hline Antrim & 10.0 & 8.6 & 3.4 & 26.9 & 96.8 & 95.2 & 100.0 & 93.1 & 100.0 & 93.9 \\
\hline Belfast & 33.8 & 36.0 & 20.0 & 25.4 & 80.3 & 77.2 & 77.0 & 41.7 & 51.1 & 47.8 \\
\hline Newry & 42.9 & 15.0 & 11.8 & 68.4 & 95.2 & 94.4 & 96.7 & 100.0 & 93.3 & 100.0 \\
\hline \multicolumn{11}{|l|}{ Scotland } \\
\hline Abrdn & & 2.1 & 100.0 & 100.0 & 100.0 & 100.0 & 97.1 & 91.1 & 68.3 & 46.7 \\
\hline Airdrie & 26.3 & 100.0 & 100.0 & 100.0 & 100.0 & 97.1 & 93.9 & 100.0 & 97.6 & 97.5 \\
\hline D \& Gall & 78.6 & 100.0 & 93.3 & 94.4 & 100.0 & 100.0 & 87.5 & 100.0 & 100.0 & 69.2 \\
\hline Dundee & 2.8 & 8.9 & 100.0 & 100.0 & 100.0 & 100.0 & 100.0 & 100.0 & 57.6 & 66.7 \\
\hline Krkcldy & 66.7 & 61.5 & 100.0 & 96.6 & 96.6 & 100.0 & 96.9 & 100.0 & 94.7 & 54.8 \\
\hline Wales & 30.7 & 43.8 & 36.3 & 47.6 & 53.3 & 48.6 & 50.6 & 84.8 & 91.2 & 89.2 \\
\hline Bangor & 35.0 & 86.2 & 52.4 & 76.9 & 73.9 & 90.0 & 100.0 & 95.8 & 95.0 & 90.0 \\
\hline Cardff & 2.9 & 4.9 & 0.0 & 2.4 & 6.7 & 7.9 & 0.6 & 73.5 & 96.7 & 80.9 \\
\hline Clwyd & 11.1 & 45.5 & 84.2 & 83.3 & 100.0 & 85.7 & 89.5 & 83.3 & 90.0 & 100.0 \\
\hline Swanse & 92.4 & 97.3 & 94.8 & 89.8 & 98.0 & 87.5 & 98.1 & 95.7 & 82.6 & 94.9 \\
\hline Wrexm & 3.4 & 22.7 & 69.2 & 100.0 & 95.7 & 92.6 & 100.0 & 95.7 & 87.0 & 97.4 \\
\hline England & 41.5 & 37.8 & 36.9 & 38.9 & 58.8 & 63.5 & 64.5 & 64.7 & 60.5 & 59.5 \\
\hline N Ireland & 38.7 & 31.7 & 20.4 & 40.8 & 89.3 & 84.6 & 90.7 & 75.2 & 81.5 & 79.7 \\
\hline Scotland & 34.0 & 44.8 & 99.8 & 98.1 & 99.0 & 99.3 & 98.5 & 98.4 & 90.6 & 82.3 \\
\hline
\end{tabular}

Blank cells: data not available for that year 
